\title{
w-Conotoxin GVIA Mimetics that Bind and Inhibit Neuronal Cav2.2 Ion Channels
}

\section{Charlotte Elisabet Tranberg ${ }^{1, \dagger}$, Aijun Yang ${ }^{2}$, Irina Vetter ${ }^{2}$, Jeffrey R. McArthur ${ }^{3}$, Jonathan B. Baell ${ }^{4}$, Richard J. Lewis ${ }^{2}$, Kellie L. Tuck ${ }^{5, *}$ and Peter J. Duggan ${ }^{1, *}$}

1 CSIRO Materials Science and Engineering, Bag 10, Clayton South, Victoria 3169, Australia; E-Mail: 1.tranberg@deakin.edu.au

2 Institute for Molecular Bioscience, The University of Queensland, St Lucia, QLD 4072, Australia; E-Mails: aijun.yang@csiro.au (A.Y.); i.vetter@imb.uq.edu.au (I.V.); r.lewis@imb.uq.edu.au (R.J.L.)

3 Health Innovations Research Institute, RMIT University, Melbourne, Victoria 3083, Australia; E-Mail: jeffrey.mcarthur@rmit.edu.au

4 Medicinal Chemistry and Drug Action, Monash Institute of Pharmaceutical Sciences, Monash University, 381 Royal Parade, Parkville, Victoria 3052, Australia; E-Mail: Jonathan.Baell@monash.edu

5 School of Chemistry, Monash University, Clayton, Victoria 3800, Australia

$\dagger$ Current address: Faculty of Science and Technology, Deakin University, Locked Bag 20000, Geelong, Victoria 3220, Australia.

* Authors to whom correspondence should be addressed; E-Mails: peter.duggan@csiro.au (P.J.D.); kellie.tuck@monash.edu (K.L.T.); Tel.: +61-3-9545-2560 (P.J.D.); +61-3-9905-4510 (K.L.T.); Fax: +61-3-9545-2446 (P.J.D.); +61-3-9905-4597 (K.L.T.).

Received: 12 September 2012; in revised form: 10 October 2012 / Accepted: 12 October 2012 / Published: 22 October 2012

\begin{abstract}
The neuronal voltage-gated N-type calcium channel $\left(\mathrm{Ca}_{\mathrm{v}} 2.2\right)$ is a validated target for the treatment of neuropathic pain. A small library of anthranilamide-derived $\omega$-Conotoxin GVIA mimetics bearing the diphenylmethylpiperazine moiety were prepared and tested using three experimental measures of calcium channel blockade. These consisted of a ${ }^{125} \mathrm{I}-\omega$-conotoxin GVIA displacement assay, a fluorescence-based calcium response assay with SH-SY5Y neuroblastoma cells, and a whole-cell patch clamp electrophysiology assay with HEK293 cells stably expressing human $\mathrm{Ca}_{\mathrm{v}} 2.2$ channels. A subset of compounds were active in all three assays. This is the first time that compounds designed to be mimics of $\omega$-conotoxin GVIA and found to be active in the ${ }^{125} \mathrm{I}-\omega$-conotoxin GVIA displacement assay have also been shown to block functional ion channels in a dose-dependent manner.
\end{abstract}


Keywords: $\mathrm{Ca}_{\mathrm{v}} 2.2$; conotoxin; peptidomimetics; radioligand binding; $\mathrm{Ca}^{2+}$ fluorescence assay; patch clamp electrophysiology

\section{Introduction}

Neuropathic pain, a pathology of the nervous system, is often highly debilitating and is thought to affect up to one-sixth of the world's population [1]. There are numerous causes for the condition, including nerve damage resulting from surgery, trauma, infection and disease. This type of pain can be unresponsive to existing therapies. A combination of opioids, antidepressants and anticonvulsants is often prescribed, but usually only provides moderate pain relief and only in about $50 \%$ of cases $[2,3]$, thus effective treatments for neuropathic pain represent a significant unmet medical need. Neuronal voltage-gated N-type calcium channels $\left(\mathrm{Ca}_{\mathrm{v}} 2.2\right)$ are strongly implicated in chronic and neuropathic pain, but there are only three approved pain-blocking drugs that act on this channel; gabapentin, pregabalin and ziconotide [1]. Small molecule inhibitors of $\mathrm{Ca}_{\mathrm{v}} 2.2$ are potential leads for the treatment of neuropathic pain and have therefore been widely pursued in industry and academia [4-6]. Recent reports include those from Neuromed Pharmaceuticals (now Zalicus) [7-10], Abbott [11-13], Merck [14,15] and Janssen [16], with Neuromed's NMED-160 reaching Phase II trials before being voluntarily withdrawn due to bioavailability issues. Reformulation of NMED-160, by Zalicus, gave Z160 which has now successfully completed Phase I trials. Phase II trials are due to commence in the second half of 2012 [10].

The $\omega$-conotoxins are a family of calcium channel-blocking cystine knot peptides found in the venom of fish-hunting marine cone snails [17-19]. The most widely studied $\mathrm{Ca}_{\mathrm{v}} 2.2$ blockers from this class are $\omega$-conotoxins GVIA, MVIIA and CVID. Ziconotide (also known as Prialt) is a synthetic version of $\omega$-conotoxin MVIIA and is used in the clinic as a primary alternative to opioids for the management of intractable chronic pain. While this drug does not appear to lead to tolerance, its intrathecal delivery, narrow therapeutic index and side effect profile means that it suffers from high dropout rates and is far from an ideal treatment [20]. $\omega$-Conotoxin CVID is more selective for $\mathrm{Ca}_{\mathrm{v}} 2.2$ channels and is expected to have greater therapeutic potential. This peptide reached Phase II in 2004 and is still being investigated under the name Leconotide [21,22]. Of the three peptides, $\omega$-conotoxin GVIA has the highest affinity for the $\mathrm{Ca}_{\mathrm{v}} 2.2$ channel, but its virtual irreversible binding makes it unattractive as a therapeutic drug. The highly constrained nature of these peptides and the availability of SAR data make them ideal starting points for the development of peptidomimetics [23,24]. Mimics of all three of these peptides have been developed, beginning with the work of Horwell and co-workers at Parke-Davis, who prepared three-residue non-peptidic mimics of $\omega$-conotoxin MVIIA based on a phloroglucinol core [25-27]. Subsequently, Lewis' group developed a cyclic pentapeptide that mimics the action of $\omega$-conotoxin CVID [28]. We have been investigating non-peptidic mimics of $\omega$-conotoxin GVIA based on benzothiazole [29,30] and anthranilamide [31,32] cores. These mimics, which bear tyrosine, lysine and arginine side chain mimics projected from a central scaffold were designed based on Bartlett and Lauri's $\mathrm{C} \alpha-\mathrm{C} \beta$ bond vector philosophy, but-crucially-not involving automated scaffold retrieval but rather interactive de novo design [23,24,33]. 
An investigation of the mimic based on the anthranilamide scaffold involved variation of the length of the side chains, the incorporation of two guanidino moieties, and two variations of the diphenyl ether substituent (see Figure 1) [32]. Key findings from this study were that; (a) typically diguanidino compounds $\left[\mathrm{Z}=\mathrm{N}=\left(\mathrm{NH}_{2}\right)_{2}\right]$ had binding activity in the $6-16 \mu \mathrm{M}$ range in a radio-labelled $\omega$-conotoxin GVIA displacement assay, whereas diamino compounds $\left[\mathrm{Z}=\mathrm{NH}_{2}\right]$ bound more weakly and; (b) strongest affinity was found with a fluorinated mimic $[\mathrm{X}=\mathrm{F}]$.

Figure 1. Previously described $\omega$-conotoxin mimics based on an anthranilamide scaffold [32].

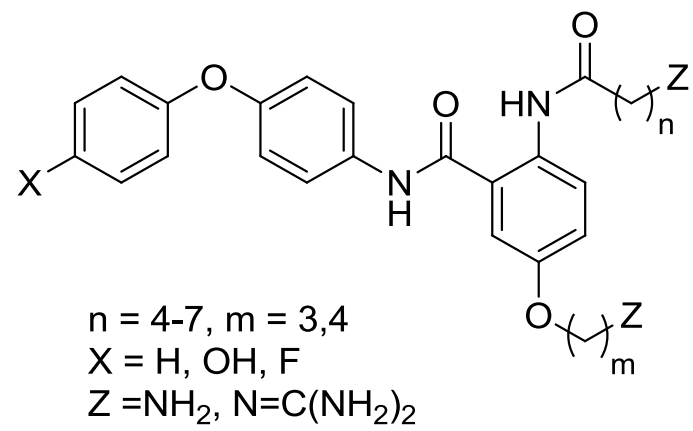

There are a number of compounds that effectively block voltage-gated calcium channels that bear the diphenylmethylpiperazine moiety [34]. Relevant to the current study are Neuromed's NP-118809 (NMED-160) [7,8] and Abbott's A-1048400 [11,12] shown in Figure 2. It was thus decided to prepare analogues of the anthranilamide-based conotoxin mimics where a diphenylmethylpiperazine moiety was incorporated in place of the phenoxyaniline substituent (Figure 3), and test their ability to block neuronal calcium channels in non-functional and, importantly, functional assays.

Figure 2. Recently published $\mathrm{Ca}_{\mathrm{v}} 2.2$ blockers bearing the diphenylpiperazine moiety.<smiles>O=C(CC(c1ccccc1)c1ccccc1)N1CCN(C(c2ccccc2)c2ccccc2)CC1</smiles>

NP-118809<smiles>O=C(CN1CCCC(c2ccccc2)(c2ccccc2)C1=O)N1CCN(C(c2ccccc2)c2ccccc2)CC1</smiles>

A-1048400

Figure 3. Analogues targeted in this study.<smiles>[Z]N=C(N)C(=O)Nc1ccc(O[Y4])cc1C(=O)N1CCN(C([Z])[Y])CC1</smiles> 


\section{Results and Discussion}

\subsection{Chemistry}

The previously described synthetic route to the anthranilamide-based mimics [32] was modified to allow incorporation of the diphenylmethylpiperazine moiety at a later stage in the synthesis, thus facilitating the preparation of a small library of compounds from a common, advanced precursor. This advanced precursor was the diazide (5), which was prepared in four steps from the previously reported nitro ester (1) [32], as shown in Scheme 1. This involved reduction of the nitro compound (1) to the aniline (2), acylation with 6-bromohexanoyl chloride to give the dihalide (3), conversion to the diazide (4) with in situ-formed tetra- $n$-butyl ammonium azide [35], and cleavage of the $t$-butyl ester.

Scheme 1. Reagents and conditions: (a) $\mathrm{H}_{2}, \mathrm{Pd} / \mathrm{C}$, ethanol; (b) 6-bromohexanoyl chloride, Triethylamine $\left(\mathrm{Et}_{3} \mathrm{~N}\right)$, Dichloromethane $\left(\mathrm{CH}_{2} \mathrm{Cl}_{2}\right)$; (c) Trimethylsilylazide (TMS-N $)_{3}$, Tetrabutylammonium fluoride (TBAF), Tetrahydrofuran (THF); (d) Trifluoroacetic acid (TFA), THF.

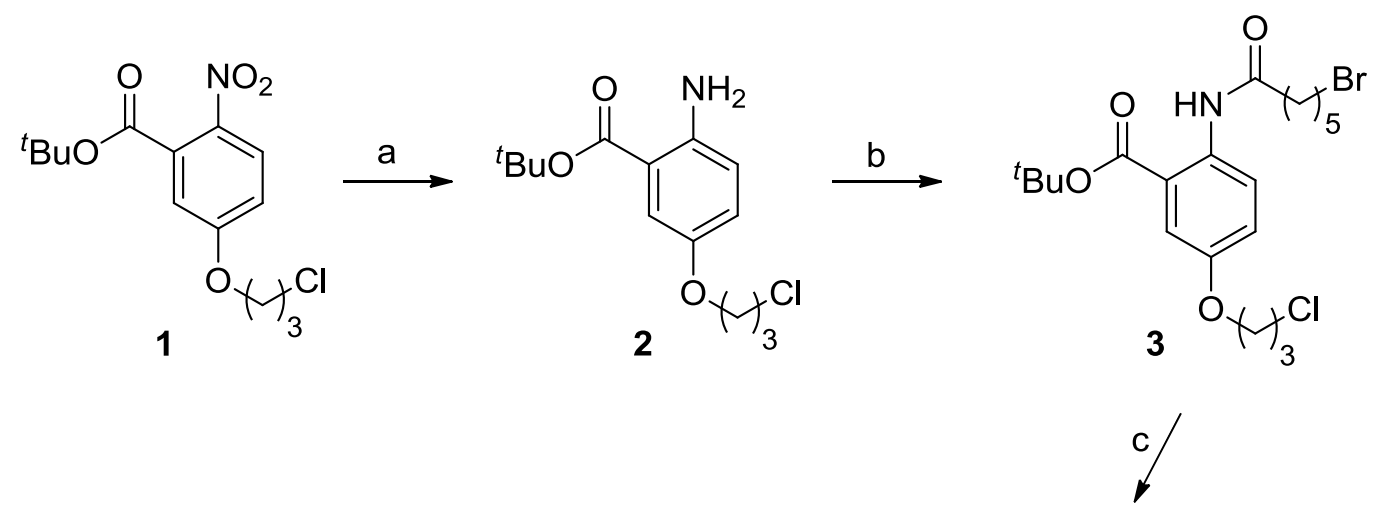<smiles>COc1ccc(NC(=O)C(C)(N)C(C)(C)N)c(C(=O)O)c1</smiles><smiles>CCCCC(C)(C)C(=O)Nc1ccc(OC)cc1C(=O)NC(C)(C)C</smiles>

A small set of compounds was prepared in which the phenoxyaniline substituent of the original anthranilamide-based mimics was replaced with fluorinated and unfluorinated diphenylmethylpiperazine, 1,3-benzodioxomethylpiperazine and phenylmethylpiperidine substituents. The latter two substituents were chosen to test the importance of the presence of the diphenylmethyl functionality to $\mathrm{Ca}_{\mathrm{v}} 2.2$ activity. The required diamines $(\mathbf{7 a}-\mathbf{d})$ and diguanidino compounds $(\mathbf{8 a}-\mathbf{d})$ were prepared from diazido acid (5) in three steps, as shown in Scheme 2. This involved the use of a DCC-assisted amidation protocol described by Shpiro and Marquez [36] to give 6a-d, reduction of the azide functionalities with dithiothreitol [37], to give $\mathbf{7 a}-\mathbf{d}$, and guanidine formation by treatment with $1 H$-pyrazole-carboxamidine [38] to give $\mathbf{8 a}-\mathbf{d}$. 
Scheme 2. Reagents and conditions: (a) Dicyclohexylcarbodiimide (DCC), Hydroxybenzotriazole (HOBt), Dimethylformamide (DMF), cyclic secondary amine, Diisopropylethylamine (DIPEA), DMF/THF (1:1); (b) dithiothreitol, $\mathrm{Et}_{3} \mathrm{~N}$, methanol; (c) $1 H$-pyrazole-carboxamidine hydrochloride, DIPEA, DMF. For $\mathbf{6 a}-\mathbf{8 a}$, $\mathrm{X}=(\mathrm{Ph})_{2} \mathrm{CH}-\mathrm{N}$; for $\mathbf{6 b}-\mathbf{8 b}, \mathrm{X}=(4-\mathrm{F}-\mathrm{Ph})_{2} \mathrm{CH}-\mathrm{N}$; for $\mathbf{6 c}-\mathbf{8 c}, \mathrm{X}=\mathrm{Ph}-\mathrm{CH}$; for $\mathbf{6 d}-\mathbf{8 d}$, $\mathrm{X}=1,3$-Benzodioxolan-5-yl- $\mathrm{CH}_{2}-\mathrm{N}$.

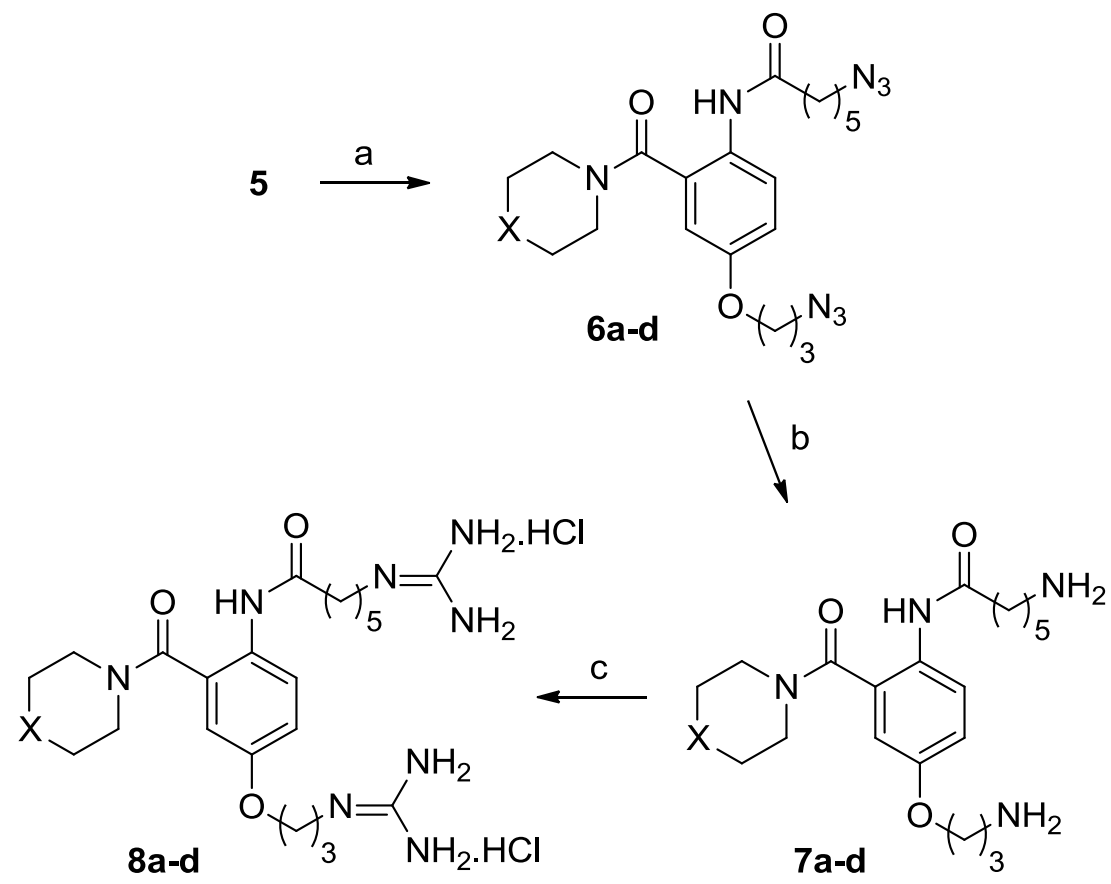

\subsection{Biology}

\subsubsection{Radioligand Displacement Assay}

The synthesized compounds, diamino (7a-d) and diguanidinium $(\mathbf{8 a}-\mathbf{d})$, were initially evaluated for their ability to bind to rat brain $\mathrm{Ca}_{\mathrm{v}} 2.2$ channels using a previously described radioligand displacement assay [29-32,39], employing ${ }^{125}$ I-labelled $\omega$-conotoxin GVIA. Although not a functional assay, the high selectivity of $\omega$-conotoxin GVIA for $\mathrm{Ca}_{\mathrm{v}} 2.2$ channels means that compounds able to displace ${ }^{125}$ I-labelled $\omega$-conotoxin GVIA from rat brain homogenate are likely to be functional inhibitors of $\mathrm{Ca}_{\mathrm{v}} 2.2$ channels. The results obtained with $\mathbf{7 a}-\mathbf{d}$ and $\mathbf{8 a}-\mathbf{d}$ are summarized in Table 1.

The affinities of the compounds that lack the diphenylmethyl functionality (7c, 7d, 8c and 8d) were too weak to be measured by this method, whereas those that do possess that moiety $(7 \mathbf{a}, 7 \mathbf{7 b}, \mathbf{8 a}$ and $\mathbf{8 b})$ showed moderate to good binding (see Figure 4). As observed previously with this class of compound [32], the diguandino compounds (8a and $\mathbf{8 b}$ ) showed strongest binding, comparable to some of the best reported anthranilamides [32], determined by this method. Compounds 7a, 7b, 8a and $\mathbf{8 b}$ were therefore selected for follow-up functional assays. 
Table 1. $\mathrm{Ca}_{\mathrm{v}} 2.2$ binding affinities of diamino (7a-d) and diguanidinium (8a-d) anthranilamides, as determined by displacement of ${ }^{125}$ I-GVIA from rat brain homogenate (95\% confidence intervals are shown in parentheses).

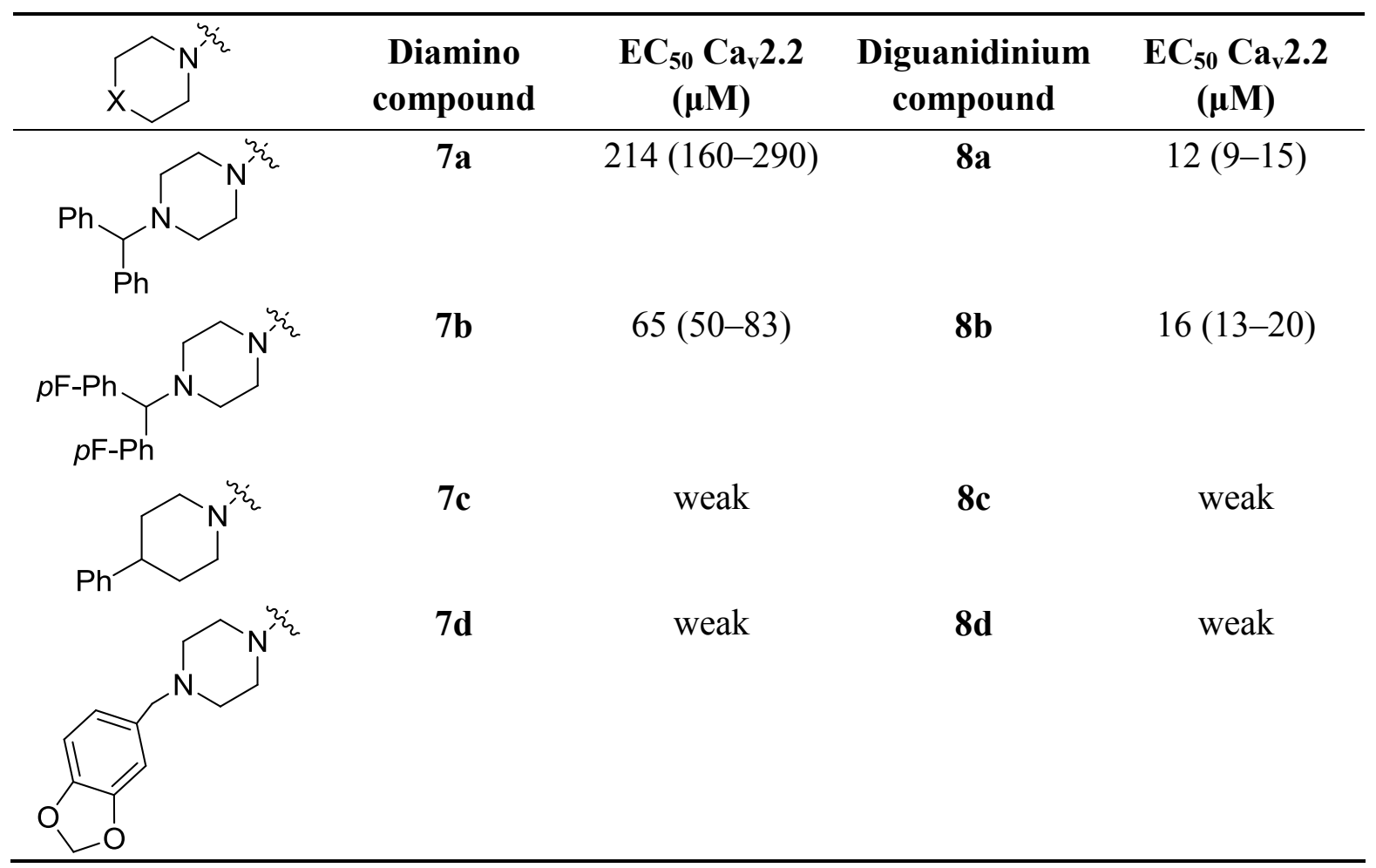

Figure 4. Dose-response curves for the displacement of ${ }^{125} \mathrm{I}$-GVIA from rat brain homogenate by diamino (7a and $\mathbf{7 b}$ ) and diguanidinium (8a and $\mathbf{8 b}$ ) compounds. $\mathrm{cpm}=$ counts per minute.

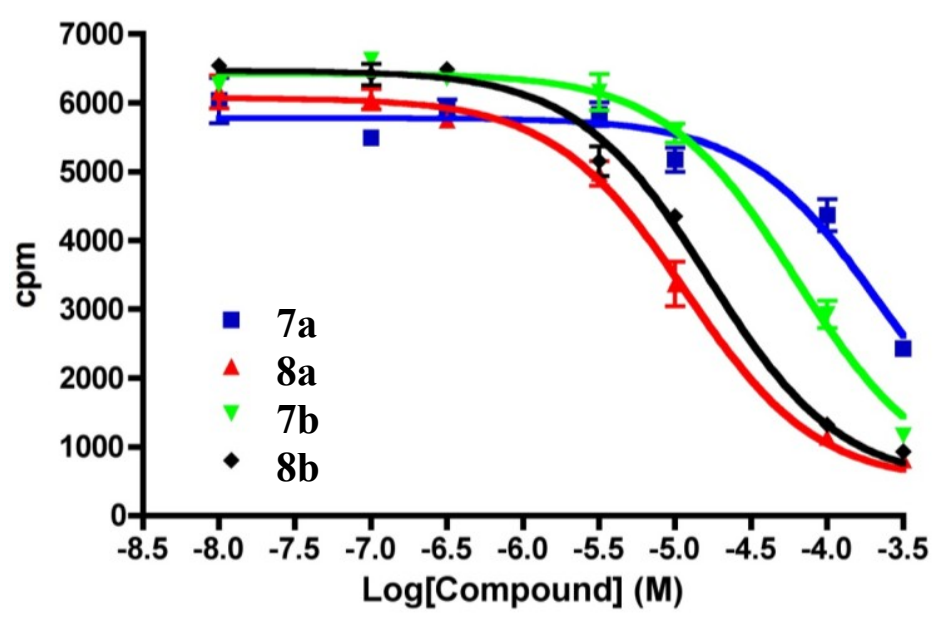

2.2.2. Inhibition of Neuroblastoma Intracellular Calcium Responses, Determined by Fluorescence Measurement of Calcium Flux

The abilities of the diamino (7a and $7 \mathbf{b}$ ) and diguanidinium (8a and $\mathbf{8 b}$ ) compounds to inhibit intracellular calcium responses in SH-SY5Y human neuroblastoma cells, in the presence of the L-type calcium channel blocker nifedipine were assessed using a high-throughput $\mathrm{Ca}^{2+}$ fluorescence assay. It was found that $\mathrm{Ca}^{2+}$ ion channel responses elicited by $\mathrm{KCl}$-mediated depolarization were partially 
inhibited by the test compounds at concentrations which did not produce fluorescence addition artefacts $(100 \mu \mathrm{M}$; Figure $5 \mathrm{~A})$, with compound $\mathbf{7 b}$ being less efficacious ( $4.9 \pm 1.8 \%$ inhibition) than compounds $7 \mathbf{a}(23.1 \pm 1.5 \%$ inhibition), $\mathbf{8 a}(20.3 \pm 4.0 \%$ inhibition $)$ and $\mathbf{8 b}(24.4 \pm 1.5 \%$ inhibition). While these inhibitory effects are not strong, dose-dependent inhibition was observed (Figure 5B) which allowed the estimation of IC50's for the functional inhibition of intracellular calcium responses in SH-SY5Y human neuroblastoma cells. These results are shown in Table 2. The estimated IC50s from these functional, whole-cell experiments are up to an order of magnitude weaker than those obtained from the radioligand displacement assay. A similar shift in potency is observed with the $\omega$-conotoxins, whose effectiveness is reduced in the presence of physiological $\mathrm{Ca}^{2+}$ levels [40] and auxiliary subunits [41], which are likely to dissociate from the $\mathrm{Ca}_{\mathrm{v}} \alpha$-subunit in membrane preparations used in radioligand displacement assays. It is also plausible that the decreased potency of the test compounds in the functional assays, in addition to effects of co-expressed auxiliary subunits, may have been influenced by relatively short incubation times in the presence of extracellular divalent cations, which has been reported to affect the on-rate of $\omega$-conotoxin block.

Figure 5. Inhibition of calcium responses from SH-SY5Y human neuroblastoma cells by diamino (7a and $\mathbf{7 b}$ ) and diguanidinium (8a and $\mathbf{8 b}$ ) compounds. (A) Calcium channel-mediated $\mathrm{Ca}^{2+}$ transients were partially inhibited by pre-treatment with compounds $7 \mathbf{a}$, 8a and $8 \mathbf{b}$ at $100 \mu \mathrm{M}$. (B) Dose-response curves for functional inhibition of calcium responses.
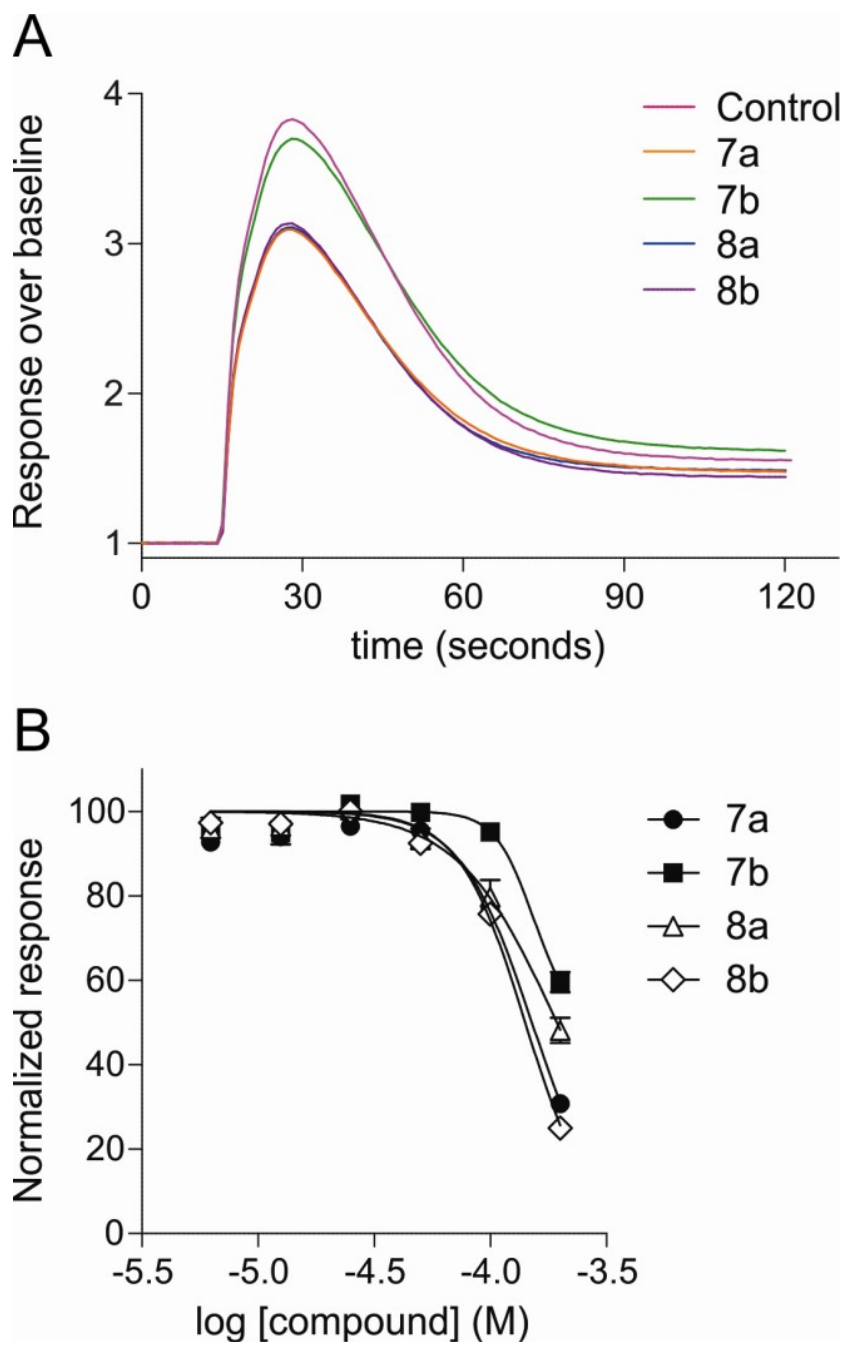
Table 2. Estimated $\mathrm{IC}_{50}$ values $(\mu \mathrm{M}$; mean $\pm \mathrm{SEM})$ for the functional inhibition of calcium channels by compounds $7 \mathbf{a}, 7 \mathbf{b}, 8 \mathbf{a}$ and $8 \mathbf{b}$.

\begin{tabular}{ccc}
\hline \multirow{2}{*}{ Compound } & $\begin{array}{c}\text { SH-SY5Y } \\
\text { neuroblastoma cells }\end{array}$ & $\begin{array}{c}\text { HEK293 } \\
\text { Ca } \boldsymbol{2} \mathbf{2 . 2}+\boldsymbol{\beta 3}+\boldsymbol{\alpha} \boldsymbol{2} \boldsymbol{\delta} \mathbf{1}\end{array}$ \\
\hline $\mathbf{7 a}$ & $160 \pm 3.6$ & $232 \pm 23$ \\
$\mathbf{7 b}$ & $286 \pm 66$ & $288 \pm 49$ \\
$\mathbf{8 a}$ & $206 \pm 50$ & $299 \pm 43$ \\
$\mathbf{8 b}$ & $156 \pm 10$ & $156 \pm 21$ \\
\hline
\end{tabular}

Despite giving comparable radioligand displacement assay results to the best previously reported anthranilamides (see Figure 1) [32], the new diphenylmethylpiperazine-substituted compounds (7a, 8a and 8b) showed superior inhibition of intracellular calcium responses in SH-SY5Y cells (data not shown) and hence can be considered an improvement on previous designs.

\subsubsection{Patch-Clamp Electrophysiology Experiments with HEK293 Cells Expressing $\mathrm{Ca}_{\mathrm{v}} 2.2$} Calcium Channels

SH-SY5Y human neuroblastoma cells contain a number of calcium channel subtypes [42-45]. To specifically measure the effect of the diamino (7a and $7 \mathbf{b}$ ) and diguanidinium (8a and $\mathbf{8 b}$ ) anthranilamides on N-type $\left(\mathrm{Ca}_{\mathrm{v}} 2.2\right)$ calcium channel currents, electrophysiological patch-clamp studies were carried out on HEK293 cells stably expressing human $\mathrm{Ca}_{\mathrm{v}} 2.2(a 1+\beta 3+\alpha 2 \delta 1$ subunits). Compounds $\mathbf{7 a}, \mathbf{7 b}$ and $\mathbf{8 a}$ were each tested at two concentrations (30 and $100 \mu \mathrm{M})$, whereas $\mathbf{8 b}$ was only tested at $30 \mu \mathrm{M}$. Representative traces obtained prior to compound application (Control) and following application of compound $7 \mathbf{a}$ at 30 and $100 \mu \mathrm{M}$ are shown in Figure 6A. The time course of washing in and out of compound $7 \mathbf{a}$ is shown in Figure $6 \mathrm{~B}$, with peak current amplitude being measured at $10 \mathrm{~s}$ intervals. All four compounds showed a modest inhibition of the calcium current amplitude; $10 \%-17 \%$ at $30 \mu \mathrm{M}$ and $20 \%-27 \%$ at $100 \mu \mathrm{M}$ (Figure $6 \mathrm{C}$ ), while exhibiting no shift in the $\mathrm{G}-\mathrm{V}$ relationship or changes to channel inactivation. To determine an approximate $\mathrm{IC}_{50}$ value, the data were fit assuming that these compounds completely inhibited the calcium currents, with a Hill coefficient of -1 . This gave the predicted half-maximal inhibition $\left(\mathrm{IC}_{50}\right.$ 's) shown in Table 2 and are consistent with those obtained using the FLIPR-Ca ${ }^{2+}$ assay in SH-SY5Y cells. The estimated $\mathrm{IC}_{50}$ values for $\mathbf{8 b}$ obtained from the two techniques are in close agreement and, of all the compounds examined in this study, this compound appears to most effectively block $\mathrm{Ca}_{\mathrm{v}} 2.2$ calcium channels. 
Figure 6. Effects of diamino (7a and 7b) and diguanidinium (8a and 8b) anthranilamides on $\mathrm{Ca}_{\mathrm{v}} 2.2$ currents in HEK293 cells. (A) Superimposed whole-cell calcium currents obtained from HEK293 cells stably expressing N-type calcium channels $\left(h C a_{v} 2.2+\beta 3+\alpha 2 \delta 1\right)$, with depolarizing voltage steps from a holding potential of $-80 \mathrm{mV}$ to a test potential of $+20 \mathrm{mV}$ (150 ms). Representative currents are shown prior to compound 7a application (Control) and in the presence of compound $7 \mathbf{a}$ at two concentrations (30 and $100 \mu \mathrm{M})$. (B) Time course of inhibition of peak inward current in response to 30 and $100 \mu \mathrm{M}$ compound 7a. (C) Bar graph of the relative inhibition of peak current amplitude (1- $\mathrm{I}_{\text {compound }} / \mathrm{I}_{\text {control }}$ ) for each compound at concentrations of 30 and $100 \mu \mathrm{M}$ (number of experiments in parentheses).

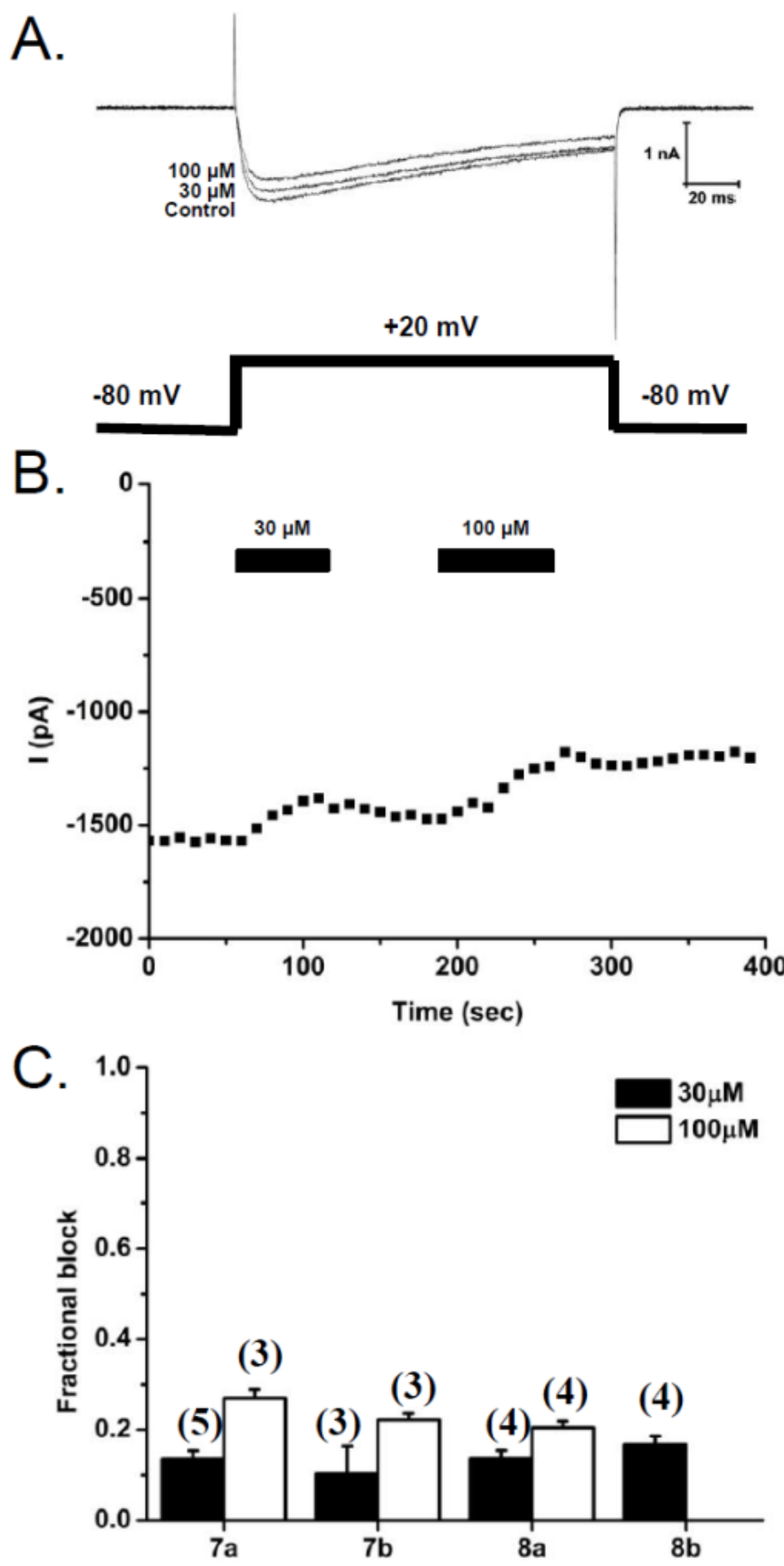




\section{Experimental Section}

\subsection{Chemistry}

\subsubsection{General Experimental Procedures}

Starting materials and reagents were purchased from Sigma-Aldrich and used without purification. Tetrahydrofuran (THF) was distilled under a nitrogen atmosphere from sodium benzophenone ketal. Dry DCM was obtained after drying over $3 \AA$ sieves. Methanol and DMF were obtained by passage through two alumina columns on the Solvent Dispensing System built by J. C. Meyer and based on the original design by Grubbs and co-workers [46]. Solutions were dried over anhydrous magnesium sulfate $\left(\mathrm{MgSO}_{4}\right)$ or sodium sulfate $\left(\mathrm{Na}_{2} \mathrm{SO}_{4}\right)$. Normal phase flash chromatography was performed on Merck silica gel No. 9385 and reverse phase chromatography was performed using a C18 Chromatorex $^{\circledR}$ DM1020T column $(30 \times 40 \mathrm{~mm})$. Spectra were recorded on a Bruker Av200 or Av400 spectrometer. Unless otherwise stated, proton $\left({ }^{1} \mathrm{H}\right) \mathrm{NMR}$ spectra were acquired at $200 \mathrm{MHz}$ and carbon $\left({ }^{13} \mathrm{C}\right) \mathrm{NMR}$ spectra at $50 \mathrm{MHz}$. NMR spectra were referenced to residual solvent peak [chloroform $\left(\delta_{\mathrm{H}} 7.26, \delta_{\mathrm{C}} 77.0\right)$, methanol $\left(\delta_{\mathrm{H}} 4.87,3.30, \delta_{\mathrm{C}} 49.86\right)$ ]. The units for all coupling constants $(J)$ are in hertz $(\mathrm{Hz})$. Low resolution mass spectra were recorded on a Micromass Platform spectrometer or VG Platform spectrometer. Accurate mass determinations were carried out at high resolution on an Agilent G1969A LC-TOF system, with reference and mass correction at $4000 \mathrm{~V}$ capillary voltage for ESI.

\subsubsection{Synthesis}

\section{tert-Butyl-2-amino-5-(3-chloropropoxy)benzoate (2)}

To a vigorously stirred flask containing tert-butyl-5-(3-chloropropoxy)-2-nitrobenzoate [32] 1 (5.17 g, $16.4 \mathrm{mmol})$ in ethanol $(100 \mathrm{~mL})$, was added $10 \%$ wt palladium on carbon $(0.17 \mathrm{~g})$. The reaction mixture was flushed with hydrogen $(3 \times)$ and then stirred under an atmosphere of hydrogen for $15 \mathrm{~h}$. The reaction mixture was filtered through Celite, the Celite thoroughly rinsed with methanol and the combined organics concentrated in vacuo. The residue was taken up in diethyl ether $(150 \mathrm{~mL})$ and washed with water and brine, then dried $\left(\mathrm{MgSO}_{4}\right)$ and concentrated to afford the title compound as an oil (4.18 $\mathrm{g}$, $89 \%)$. This compound was used in subsequent transformations without further purification. $\delta_{\mathrm{H}}\left(\mathrm{CDCl}_{3}\right)$ $1.62(\mathrm{~s}, 9 \mathrm{H}), 2.25(\mathrm{~m}, 2 \mathrm{H}), 3.75(\mathrm{t}, J=6.2 \mathrm{~Hz}, 2 \mathrm{H}), 4.15(\mathrm{t}, J=6.0 \mathrm{~Hz}, 2 \mathrm{H}), 7.17(\mathrm{dd}, J=3.0,8.8 \mathrm{~Hz}, 1 \mathrm{H})$, $7.52(\mathrm{~d}, J=3.0 \mathrm{~Hz}, 1 \mathrm{H}), 7.90(\mathrm{~d}, J=8.8 \mathrm{~Hz}, 1 \mathrm{H}) ; \delta_{\mathrm{C}}\left(\mathrm{CDCl}_{3}\right)$ 28.1, 31.9, 41.1, 64.9, 84.5, 117.3, 119.9, 123.8, 125.7, 127.0, 158.0, 166.0; $m / z\left(\mathrm{EI}^{+}\right): \mathrm{m} / z(\%): 285.1(30)[\mathrm{M}]^{+}, 229.0(100)\left[\mathrm{M}-\mathrm{C}_{4} \mathrm{H}_{9}\right]^{+}$.

\section{tert-Butyl-2-(6-bromohexanamido)-5-(3-chloropropoxy)benzoate (3)}

6-Bromohexanoyl chloride $(2.1 \mathrm{~mL}, 14 \mathrm{mmol})$ was added dropwise to the aniline $2(3.72 \mathrm{mg}$, $13.0 \mathrm{mmol})$ and triethylamine $(2.7 \mathrm{~mL}, 19 \mathrm{mmol})$ dissolved in dry DCM $(70 \mathrm{~mL})$. The reaction mixture was stirred at RT for $20 \mathrm{~h}$ and then poured into $2 \mathrm{M} \mathrm{HCl}(50 \mathrm{~mL})$. The layers were separated and the aqueous phase was extracted with DCM. The combined organic phases were washed with saturated sodium bicarbonate and brine, then dried $\left(\mathrm{MgSO}_{4}\right)$ and concentrated in vacuo to afford the amide 3 as an oil (6.02 g, quant.); $\delta_{\mathrm{H}}\left(\mathrm{CDCl}_{3}\right)$ 1.49-1.99 (complex, 6H), $1.61(\mathrm{~s}, 9 \mathrm{H}), 2.23$ (m, 2H), 
$2.44(\mathrm{t}, J=7.2 \mathrm{~Hz}, 2 \mathrm{H}), 3.42(\mathrm{t}, J=6.8 \mathrm{~Hz}, 2 \mathrm{H}), 3.75(\mathrm{t}, J=6.2 \mathrm{~Hz}, 2 \mathrm{H}), 4.11(\mathrm{t}, J=6.0 \mathrm{~Hz}, 2 \mathrm{H}), 7.08$ $(\mathrm{dd}, J=3.0,9.2 \mathrm{~Hz}, 1 \mathrm{H}), 7.47(\mathrm{~d}, J=3.0 \mathrm{~Hz}, 1 \mathrm{H}), 8.62(\mathrm{~d}, J=9.2 \mathrm{~Hz}, 1 \mathrm{H}), 10.93(\mathrm{br} \mathrm{s}, 1 \mathrm{H}) . \delta_{\mathrm{C}}$ $\left(\mathrm{CDCl}_{3}\right)$ 24.6, 27.7, 28.2, 32.2, 32.5, 33.5, 38.2, 41.4, 64.7, 82.6, 116.3, 117.7, 120.2, 121.8, 135.4, 153.3, 167.3, 171.3; $\mathrm{m} / z\left(\mathrm{ESI}^{+}, 50 \mathrm{eV}\right): \mathrm{m} / z(\%): 486.0(100)[\mathrm{M}+\mathrm{Na}]^{+}, 484.0(70), 464[\mathrm{M}+\mathrm{H}]^{+}, 462.0(20)$.

\section{tert-Butyl-2-(6-azidohexanamido)-5-(3-azidopropoxy)benzoate (4)}

The diazide 4 was prepared from the dihalide $3(5.92 \mathrm{~g}, 12.8 \mathrm{mmol})$ by treatment with trimethylsilylazide (95\% purity, $5.4 \mathrm{~mL}, 39 \mathrm{mmol})$ and tetra- $n$-butylammonium fluoride $(1.0 \mathrm{M}$ in THF, $38.4 \mathrm{~mL}, 38.4 \mathrm{mmol}$ ) in THF following the method of Takaya [35]. Care was taken to ensure the diazide was not subjected to shock or heat. The diazide 4 was obtained as a light brown oil which was purified by flash chromatography (20: $1 \mathrm{DCM} / \mathrm{MeOH})$ to afford a cream-colored solid (4.09 $\mathrm{g}, 74 \%$ ). $\delta_{\mathrm{H}}\left(\mathrm{CDCl}_{3}\right) 1.40-1.85$ (complex, 6H), $1.59(\mathrm{~s}, 9 \mathrm{H}), 2.02(\mathrm{~m}, 2 \mathrm{H}), 2.42(\mathrm{t}, J=7.2 \mathrm{~Hz}, 2 \mathrm{H}), 3.26$ (t, $J=6.6 \mathrm{~Hz}, 2 \mathrm{H}), 3.50(\mathrm{t}, J=6.6 \mathrm{~Hz}, 2 \mathrm{H}), 4.02(\mathrm{t}, J=5.8 \mathrm{~Hz}, 2 \mathrm{H}), 7.05(\mathrm{dd}, J=3.2,9.2 \mathrm{~Hz}, 1 \mathrm{H})$, $7.44(\mathrm{~d}, J=3.2 \mathrm{~Hz}, 1 \mathrm{H}), 8.60(\mathrm{~d}, J=9.2 \mathrm{~Hz}, 1 \mathrm{H}), 10.92(\mathrm{br} \mathrm{s}, 1 \mathrm{H}) ; \delta_{\mathrm{C}}\left(\mathrm{CDCl}_{3}\right) 25.0,26.3,28.1,28.6$, 28.7, 38.2, 48.1, 51.2, 64.9, 82.6, 116.2, 117.6, 120.2, 121.8, 135.4, 153.2, 167.2, 171.3; $\mathrm{m} / \mathrm{z}\left(\mathrm{ESI}^{+}, 50 \mathrm{eV}\right)$ : $m / z(\%): 454.6(15)[\mathrm{M}+\mathrm{Na}]^{+}, 432.7(100)[\mathrm{M}+\mathrm{H}]^{+}$.

\section{2-(6-Azidohexanamido)-5-(3-azidopropoxy)benzoic acid (5)}

To a solution of $4(1.31 \mathrm{~g}, 3.05 \mathrm{mmol})$ in dry DCM $(10 \mathrm{~mL})$ was added TFA $(10 \mathrm{~mL})$ dropwise. After stirring the reaction mixture at RT for $4 \mathrm{~h}$ it was poured into water $(20 \mathrm{~mL})$ and extracted with DCM $(2 \times 10 \mathrm{~mL})$. The organic phase was dried, and concentrated in vacuo to yield the title compound as a solid $(1.14 \mathrm{~g}, 99 \%) . \delta_{\mathrm{H}}\left(\mathrm{CDCl}_{3}\right) 1.43-1.87$ (complex, $\left.6 \mathrm{H}\right), 2.05(\mathrm{~m}, 2 \mathrm{H}), 2.48(\mathrm{t}, J=7.2 \mathrm{~Hz}, 2 \mathrm{H})$, $3.28(\mathrm{t}, J=6.6 \mathrm{~Hz}, 2 \mathrm{H}), 3.52(\mathrm{t}, J=6.4 \mathrm{~Hz}, 2 \mathrm{H}), 4.06(\mathrm{t}, J=5.8 \mathrm{~Hz}, 2 \mathrm{H}), 7.16(\mathrm{dd}, J=3.0,9.2 \mathrm{~Hz}$, $1 \mathrm{H}), 7.61(\mathrm{~d}, J=3.0 \mathrm{~Hz}, 1 \mathrm{H}), 8.64(\mathrm{~d}, J=9.2 \mathrm{~Hz}, 1 \mathrm{H}), 10.86(\mathrm{br} \mathrm{s}, 1 \mathrm{H}) ; \delta_{\mathrm{C}}\left(\mathrm{CDCl}_{3}\right)$ 25.1, 26.2, 28.5, 28.7, 38.1, 48.1, 51.2, 65.0, 116.0, 116.6, 121.6, 122.1, 172.2, 135.3, 153.7, 170.9; $\mathrm{m} / \mathrm{z}\left(\mathrm{ESI}^{+}, 50 \mathrm{eV}\right)$ : $m / z(\%): 398.6(100)[\mathrm{M}+\mathrm{Na}]^{+}, 376.5(70)[\mathrm{M}+\mathrm{H}]^{+}$.

\section{6-Azido- $N$-(4-(3-azidopropoxy)-2-(4-benzhydrylpiperazine-1-carbonyl)phenyl)hexanamide (6a)}

The title compound was prepared following an amidation procedure used by Marquez and Shpiro [36]. To a solution of the diazide $5(120 \mathrm{mg}, 0.33 \mathrm{mmol})$ in anhydrous THF and DMF $(1: 1,3.2 \mathrm{~mL})$ was added DCC (100 mg, $0.49 \mathrm{mmol})$. After the reaction mixture was stirred at RT for $15 \mathrm{~min}, \mathrm{HOBt}$ (70 mg, $0.49 \mathrm{mmol})$ and 4-DMAP ( $8 \mathrm{mg}, 0.06 \mathrm{mmol})$ were added. After $1.5 \mathrm{~h}, 1$-benzhydrylpiperazine (170 mg, $0.65 \mathrm{mmol})$ and DIPEA $(0.17 \mathrm{~mL}, 0.98 \mathrm{mmol})$ were sequentially added. After stirring at RT for $24 \mathrm{~h}$, the mixture was filtered, the precipitate washed with DCM and solvent was removed in vacuo. Purification by flash chromatography (3:1 PET spirit 40-60/ethyl acetate) gave the title compound 6a as a solid $(130 \mathrm{mg}, 66 \%) ; \delta_{\mathrm{H}}\left(\mathrm{CDCl}_{3}\right) 1.40-1.80$ (complex, 6H), $2.01(\mathrm{~m}, 2 \mathrm{H}), 2.32(\mathrm{t}, J=7.2 \mathrm{~Hz}, 2 \mathrm{H})$, 2.40 (br s, 4H), 3.30 (t, $J=6.6 \mathrm{~Hz}, 2 \mathrm{H}), 3.48$ (t, $J=6.6 \mathrm{~Hz}, 2 \mathrm{H}), 3.71$ (br s, 4H), 3.98 (t, $J=6.0 \mathrm{~Hz}$, 2H), $4.26(\mathrm{~s}, 1 \mathrm{H}), 6.70(\mathrm{~d}, J=2.8 \mathrm{~Hz}, 1 \mathrm{H}), 6.89(\mathrm{dd}, J=3.0,9.0 \mathrm{~Hz}, 1 \mathrm{H}), 7.15-7.43(\mathrm{~m}, 10 \mathrm{H}), 8.01$ $(\mathrm{d}, J=8.0 \mathrm{~Hz}, 1 \mathrm{H}), 8.49$ (br s, $1 \mathrm{H}) ; \delta_{\mathrm{C}}\left(\mathrm{CDCl}_{3}\right)$ 25.1, 26.3, 28.6, 28.7, 37.3, 48.1, 51.2, 51.9 (br), 52.1 (br), 
65.0, 75.9, 113.4, 116.0, 125.0, 126.5, 127.2, 127.8, 128.6, 129.6, 141.9, 154.4, 168.3, 171.1; $m / z\left(\mathrm{ESI}^{+}, 50 \mathrm{eV}\right): m / z(\%): 632.3(10)[\mathrm{M}+\mathrm{Na}]^{+}, 610.3(50)[\mathrm{M}+\mathrm{H}]^{+}$.

\section{6-Azido- $N$-(4-(3-azidopropoxy)-2-(4-(bis(4-fluorophenyl)methyl)piperazine-1-carbonyl) phenyl)hexanamide (6b)}

The title compound $\mathbf{6 b}$ was prepared from 5 and 1-(bis(4-fluorophenyl)methyl)piperazine according to the procedure used to prepare 6a, except that the reaction mixture was stirred at RT for $56 \mathrm{~h}$. Purification by flash chromatography (2:1 PET spirit 40-60/ethyl acetate) gave $6 \mathbf{b}(140 \mathrm{mg}, 85 \%)$. $\delta_{\mathrm{H}}$ $\left(\mathrm{CDCl}_{3}\right) 1.39-1.79(\mathrm{~m}, 6 \mathrm{H}), 2.01(\mathrm{~m}, 2 \mathrm{H}), 2.31(\mathrm{t}, J=7.6 \mathrm{~Hz}, 2 \mathrm{H}), 2.36($ br s, $4 \mathrm{H}), 3.29$ (t, $J=6.8 \mathrm{~Hz}$, 2H), $3.48(\mathrm{t}, J=6.4 \mathrm{~Hz}, 2 \mathrm{H}), 3.73(\mathrm{br} \mathrm{s}, 4 \mathrm{H}), 3.98(\mathrm{t}, J=6.0 \mathrm{~Hz}, 2 \mathrm{H}), 4.24(\mathrm{~s}, 1 \mathrm{H}), 6.68(\mathrm{~d}, J=2.8 \mathrm{~Hz}$, $1 \mathrm{H}), 6.89(\mathrm{dd}, J=2.8,9.0 \mathrm{~Hz}, 1 \mathrm{H}), 6.92-7.02(\mathrm{~m}, 4 \mathrm{H}), 7.29-7.36(\mathrm{~m}, 4 \mathrm{H}),, 7.95(\mathrm{~d}, J=9.0 \mathrm{~Hz}, 1 \mathrm{H})$, 8.50 (br s, $1 \mathrm{H}) ; \delta_{\mathrm{C}}\left(\mathrm{CDCl}_{3}\right)$ 25.1, 26.3, 28.6, 28.7, 37.2, 48.1, 51.2, 51.7 (br), 65.0, 74.2, 113.4, 115.6 $(\mathrm{d}, J=21.6 \mathrm{~Hz}), 116.0,125.3,126.8,129.1,129.2(\mathrm{~d}, J=7.9 \mathrm{~Hz}), 137.4(\mathrm{~d}, J=3.0 \mathrm{~Hz}), 154.5,161.9$ $(\mathrm{d}, J=246.5 \mathrm{~Hz}), 168.4,171.2 ; \mathrm{m} / z\left(\mathrm{ESI}^{+}, 50 \mathrm{eV}\right): \mathrm{m} / z(\%): 668.3(10)[\mathrm{M}+\mathrm{Na}]^{+}, 646.3(35)[\mathrm{M}+\mathrm{H}]^{+}$.

\section{6-Azido- $N$-(4-(3-azidopropoxy)-2-(4-phenylpiperidine-1-carbonyl)phenyl)hexanamide (6c)}

The title compound $\mathbf{6 c}$ was prepared from $\mathbf{5}$ and 4-phenylpiperidine according to the procedure used to prepare 6a. Purification by flash chromatography (1:1 PET spirit 40-60/ethyl acetate) gave 6c (190 mg, 93\%); $\delta_{\mathrm{H}}\left(\mathrm{CDCl}_{3}\right)$ 1.37-2.00 (methylene envelope, $\left.10 \mathrm{H}\right), 2.02(\mathrm{~m}, 2 \mathrm{H}), 2.32(\mathrm{t}, J=6.0 \mathrm{~Hz}, 2 \mathrm{H}), 2.78$ $(\mathrm{m}, 1 \mathrm{H}), 3.00(\mathrm{br} \mathrm{s}, 2 \mathrm{H}), 3.25(\mathrm{t}, J=6.0 \mathrm{~Hz}, 2 \mathrm{H}), 3.49(\mathrm{t}, J=6.0 \mathrm{~Hz}, 2 \mathrm{H}), 4.01(\mathrm{t}, J=6.0 \mathrm{~Hz}, 2 \mathrm{H}), 4.80$ (br s, 2H), $6.76(\mathrm{~d}, J=2.0 \mathrm{~Hz}, 1 \mathrm{H}), 6.90(\mathrm{dd}, J=2.0,6.0 \mathrm{~Hz}, 1 \mathrm{H}), 7.17-7.32(\mathrm{~m}, 5 \mathrm{H}), 7.90(\mathrm{~d}, J=8.0 \mathrm{~Hz}$, $1 \mathrm{H}), 8.63(\mathrm{~s}, 1 \mathrm{H}) ; \delta_{\mathrm{C}}\left(\mathrm{CDCl}_{3}\right)$ 24.8, 25.0, 26.2, 28.5, 28.6, 33.3 (br), 33.8, 37.0, 42.3, 48.0, 51.1, 64.9, 113.0, 115.8, 125.4, 126.5, 127.6, 128.5, 129.1, 144.6, 154.6, 168.4, 171.1; $\mathrm{m} / z\left(\mathrm{ESI}^{+}, 50 \mathrm{eV}\right): \mathrm{m} / z(\%)$ : $541.3(100)[\mathrm{M}+\mathrm{Na}]^{+}, 519.3(20)[\mathrm{M}+\mathrm{H}]^{+}$.

\section{6-Azido- $N$-(4-(3-azidopropoxy)-2-(4-((3a,7a-dihydrobenzo[d][1,3]dioxol-5-yl)methyl) piperazine-1-carbonyl)phenyl)hexanamide (6d)}

The title compound $\mathbf{6 d}$ was prepared from 5 and 1-piperonylpiperazine according to the procedure used to prepare 5. Purification by flash chromatography (5:1 PET spirit 40-60/ethyl acetate) gave 6d (200 mg, 54\%); $\delta_{\mathrm{H}}\left(400 \mathrm{MHz}, \mathrm{CDCl}_{3}\right) 1.43(\mathrm{~m}, 2 \mathrm{H}), 1.59-1.74$ (methylene envelope, 4H), 2.02 (m, 2H), 2.30 (t, $J=7.6 \mathrm{~Hz}, 2 \mathrm{H}), 2.41$ (br s, 2H), 2.47 (br s, 2H), 3.27 (t, $J=6.8 \mathrm{~Hz}, 2 \mathrm{H}), 3.44$ (s, 2H), 3.49 (t, $J=6.8 \mathrm{~Hz}, 2 \mathrm{H}), 3.75$ (br s, 4H), 4.00 (t, $J=6.0 \mathrm{~Hz}, 2 \mathrm{H}), 5.92(\mathrm{~s}, 2 \mathrm{H}), 6.70-6.72(\mathrm{~m}, 3 \mathrm{H}), 6.83$ $(\mathrm{s}, 1 \mathrm{H}), 6.89(\mathrm{dd}, J=2.8,8.8 \mathrm{~Hz}, 1 \mathrm{H}), 7.91(\mathrm{~d}, J=8.8 \mathrm{~Hz}, 1 \mathrm{H}), 8.52(\mathrm{~s}, 1 \mathrm{H}) ; \delta_{\mathrm{C}}\left(100 \mathrm{MHz}, \mathrm{CDCl}_{3}\right)$ 25.1, 26.3, 28.6, 28.7, 37.2, 48.1, 51.2, 52.6 (br), 53.0 (br), 62.4, 65.0, 101.0, 108.0, 109.4, 113.3,

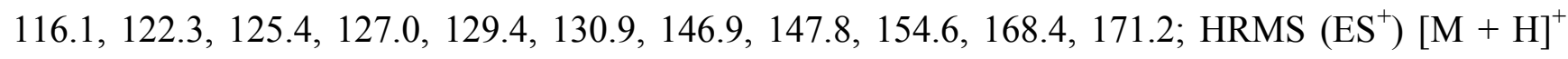
calcd for $\mathrm{C}_{28} \mathrm{H}_{36} \mathrm{~N}_{9} \mathrm{O}_{5} 578.2839$ found 578.2829. 


\section{6-Amino- $N$-(4-(3-aminopropoxy)-2-(4-benzhydrylpiperazine-1-carbonyl)phenyl)hexanamide (7a)}

A solution of $6 \mathbf{6}(140 \mathrm{mg}, 0.22 \mathrm{mmol})$ in methanol $(4.5 \mathrm{~mL})$ was treated sequentially with dithiothreitol $(20 \mathrm{mg}, 1.3 \mathrm{mmol})$ and TEA $(0.1 \mathrm{~mL}, 0.9 \mathrm{mmol})$. After the reaction mixture was stirred at room temperature for $20 \mathrm{~h}$, the solvent was removed in vacuo. Purification by reverse phase chromatography [elution with methanol/water $(90: 10,60 \mathrm{~mL})$, followed by methanol $(75 \mathrm{~mL})$ and then acetonitrile $(30 \mathrm{~mL})]$ gave $7 \mathbf{a}(60 \mathrm{mg}, 52 \%) ; \delta_{\mathrm{H}}$ (methanol- $\left.d_{4}\right) 1.35-1.60$ (complex, $\left.4 \mathrm{H}\right), 1.69(\mathrm{~m}, 2 \mathrm{H})$, 1.91 (m, 2H), 2.33 (complex, 4H), 2.45 (m, 2H), 2.67 (br t, $J=6.8 \mathrm{~Hz}, 2 \mathrm{H}), 2.82$ (br t, $J=6.9 \mathrm{~Hz}, 2 \mathrm{H}$ ), 3.38 (br s, 2H), 3.71 (br s, 2H), 4.04 (br t, $J=6.2 \mathrm{~Hz}, 2 \mathrm{H}), 4.30(\mathrm{~s}, 1 \mathrm{H}), 6.82(\mathrm{~d}, J=2.8 \mathrm{~Hz}, 1 \mathrm{H}), 6.98$ $(\mathrm{dd}, J=2.8,8.8 \mathrm{~Hz}, 1 \mathrm{H}), 7.18-7.29(\mathrm{~m}, 7 \mathrm{H}),, 7.43(\mathrm{~d}, J=6.9 \mathrm{~Hz}, 4 \mathrm{H}) ; \delta_{\mathrm{C}}$ (methanol- $\left.d_{4}\right) 26.8,27.6$, 33.2, 33.3, 37.2, 39.6, 42.3, 43.2, 49.9, 52.6, 53.1, 67.5, 77.2, 114.1, 117.2, 128.3, 129.0, 129.1, 129.7, 133.9, 143.7, 158.3, 170.0, 171.2; m/z (ESI, $50 \mathrm{eV}): \mathrm{m} / z(\%): 558.3(100)[\mathrm{M}+\mathrm{H}]^{+}, 570.3(30)$ $[\mathrm{M}+\mathrm{Na}]^{+}$. HRMS $\left(\mathrm{ESI}^{+}\right)[\mathrm{M}+\mathrm{H}]^{+}$calcd for $\mathrm{C}_{33} \mathrm{H}_{44} \mathrm{~N}_{5} \mathrm{O}_{3} 558.3444$ found 558.3460 .

\section{6-Amino- $N$-(4-(3-aminopropoxy)-2-(4-(bis(4-fluorophenyl)methyl)piperazine-1-carbonyl) phenyl)hexanamide (7b)}

The diamine $\mathbf{7 b}$ was prepared from $\mathbf{6 b}$ according to the procedure used to prepare $7 \mathbf{a}$. The product was isolated as an oil $(90 \mathrm{mg}, 75 \%) . \delta_{\mathrm{H}}$ (methanol- $\left.d_{4}\right)$ 1.36-1.75 (methylene envelope, $\left.6 \mathrm{H}\right), 1.91(\mathrm{~m}$, 2H), 2.31 (t, $J=7.4 \mathrm{~Hz}, 2 \mathrm{H}), 2.42($ br s, $4 \mathrm{H}), 2.66$ (t, $J=7.0 \mathrm{~Hz}, 2 \mathrm{H}), 2.80$ (t, $J=7.0 \mathrm{~Hz}, 2 \mathrm{H}), 3.38$ (br s, 2H), 3.70 (br s, 2H), 4.03 (t, $J=6.0 \mathrm{~Hz}, 2 \mathrm{H}), 4.35$ (s, 1H), $6.81(\mathrm{~d}, J=2.6 \mathrm{~Hz}, 1 \mathrm{H}), 6.94-7.05(\mathrm{~m}, 5 \mathrm{H})$, $7.26(\mathrm{~d}, J=8.8 \mathrm{~Hz}, 1 \mathrm{H}), 7.38-7.45(\mathrm{~m}, 4 \mathrm{H}) ; \delta_{\mathrm{C}}\left(\right.$ methanol- $\left.d_{4}\right)$ 26.7, 27.5, 32.9, 33.0, 37.1, 39.5, 42.1, 43.1, 52.4, 52.7, 67.5, 75.2, 114.1, 116.3 (d, $J=21.5 \mathrm{~Hz}), 117.0,129.0,130.7$ (d, $J=7.9 \mathrm{~Hz}), 133.7$, $139.4(\mathrm{~d}, J=3.1 \mathrm{~Hz}), 158.2,163.3(\mathrm{~d}, J=244.3 \mathrm{~Hz}), 169.9,175.0 ; \mathrm{m} / z\left(\mathrm{ESI}^{+}, 50 \mathrm{eV}\right): \mathrm{m} / z(\%): 594.3$ (100) $[\mathrm{M}+\mathrm{H}]^{+}$. HRMS $\left(\mathrm{ESI}^{+}\right)[\mathrm{M}+\mathrm{H}]^{+}$calcd for $\mathrm{C}_{33} \mathrm{H}_{42} \mathrm{~N}_{5} \mathrm{O}_{3} \mathrm{~F}_{2}(\mathrm{M}+\mathrm{H})^{+} 594.3256$ found 594.3259.

\section{6-Amino- $N$-(4-(3-aminopropoxy)-2-(4-phenylpiperidine-1-carbonyl)phenyl)hexanamide (7c)}

The diamine 7c was prepared from $\mathbf{6 c}$ according to the procedure used to prepare 7a. Purification by reverse phase chromatography [elution with methanol/water (80:20)] gave 7c as an oil (120 mg, 99\%); $\delta_{\mathrm{H}}\left(400 \mathrm{MHz}\right.$, methanol- $\left.d_{4}\right)$ 1.39-1.60 (methylene envelope, 4H), $1.72(\mathrm{~m}, 4 \mathrm{H}), 1.95(\mathrm{~m}, 2 \mathrm{H}), 2.37$ (m, 2H), 2.68 (m, 2H), 2.80-2.91 (complex, 5H), 3.17 (br s, 2), 3.76 (br d, $J=13.2 \mathrm{~Hz}, 1 \mathrm{H}$ ), 4.07 $(\mathrm{t}, J=6.0 \mathrm{~Hz}, 2 \mathrm{H}), 4.74(\mathrm{~d}, J=12.0 \mathrm{~Hz}, 1 \mathrm{H}), 6.90(\mathrm{~s}, 1 \mathrm{H}), 7.01(\mathrm{dd}, J=2.4,8.4 \mathrm{~Hz}, 1 \mathrm{H}), 7.18-7.43$ $(\mathrm{m}, 6 \mathrm{H}) ; \delta_{\mathrm{C}}$ (methanol- $\left.d_{4}\right) 25.3,26.1,31.1,31.4,32.7,33.3,35.7,38.1,40.6,42.2,66.1,112.5,115.5$, $126.1,126.4,126.8,127.7,128.2,132.8,145.3,156.9,168.5,173.6 ; \mathrm{m} / z\left(\mathrm{ESI}^{+}, 50 \mathrm{eV}\right): \mathrm{m} / \mathrm{z}(\%): 467.3$ (100) $[\mathrm{M}+\mathrm{H}]^{+}, 489.3(55)[\mathrm{M}+\mathrm{Na}]^{+}$.

\section{6-Amino- $N$-(4-(3-aminopropoxy)-2-(4-(benzo[d][1,3] dioxol-5-ylmethyl)piperazine-1-carbonyl) phenyl)hexanamide (7d)}

The diamine 7d was prepared from $\mathbf{6 d}$ according to the procedure used to prepare $7 \mathbf{a}$. The product was isolated as an oil $(90 \mathrm{mg}, 61 \%) ; \delta_{\mathrm{H}}\left(\right.$ methanol- $\left.d_{4}\right) 1.37-1.76$ (methylene envelope, $\left.6 \mathrm{H}\right), 1.94(\mathrm{~m}$, 2H), 2.32 (t, $J=7.2 \mathrm{~Hz}, 2 \mathrm{H}), 2.39$ (br s, 2H), 2.50 (br s, 2H), 2.70 (t, $J=6.8 \mathrm{~Hz}, 2 \mathrm{H}), 2.84$ (t, $J=6.8 \mathrm{~Hz}$, 2H), 3.36 (br s, 2H), 3.47 (s, 2H), $3.70($ br s, 2H), $4.06(\mathrm{t}, J=6.0 \mathrm{~Hz}, 2 \mathrm{H}), 5.91(\mathrm{~s}, 2 \mathrm{H}), 6.75(\mathrm{br} \mathrm{s}, 2 \mathrm{H})$, 
6.82 (br s, 2H), $7.00(\mathrm{dd}, J=2.8,8.8 \mathrm{~Hz}, 1 \mathrm{H}), 7.28(\mathrm{~d}, J=8.8 \mathrm{~Hz}, 1 \mathrm{H}) ; \delta_{\mathrm{C}}\left(\right.$ methanol- $\left.d_{4}\right) 25.3,26.1$, 31.2, 31.5, 35.7, 38.1, 40.6, 41.4, 52.0, 52.3, 62.0, 66.1, 100.9, 107.4, 109.2, 112.6, 115.7, 122.4, 126.8, 127.7, 130.8, 132.4, 147.0, 147.8, 156.9, 168.5, 173.7; $m / z\left(\mathrm{ESI}^{+}, 50 \mathrm{eV}\right): \mathrm{m} / z(\%): 526.4$ (20) $[\mathrm{M}+\mathrm{Na}]^{+}, 477.3(30)[\mathrm{M}+\mathrm{H}]^{+}$. HRMS $\left(\mathrm{ES}^{+}\right)[\mathrm{M}+\mathrm{H}]^{+}$calcd for $\mathrm{C}_{28} \mathrm{H}_{39} \mathrm{~N}_{5} \mathrm{O}_{5} 526.3029$ found 526.3018 .

\section{$N$-2(4-Benzhydrylpiperazine-1-carbonyl)-4-(3-guanidinopropoxy)}

\section{phenyl-6-guanidinohexanamide dihydrochloride (8a)}

The diguanidinium compound 8a was prepared following the general procedure of Bernatowitcz et al. [21]. To the amine 7a $(50 \mathrm{mg}, 0.09 \mathrm{mmol})$ in DMF $(0.2 \mathrm{~mL})$ was added $1 H$-pyrazole-carboxamidine hydrochloride $(30 \mathrm{mg}, 0.17 \mathrm{mmol})$ and DIPEA $(0.03 \mathrm{~mL}, 0.17 \mathrm{mmol})$ and the reaction mixture was stirred at RT for $68 \mathrm{~h}$. The solvent was then removed in vacuo and the residue triturated with diethyl ether to give a solid that was recrystallized from ether/methanol to afford $\mathbf{8 a}$ as a glassy semisolid (45 mg, 74\%); $\delta_{\mathrm{H}}$ (methanol- $\left.d_{4}\right) 1.49(\mathrm{~m}, 2 \mathrm{H}), 1.67(\mathrm{~m}, 4 \mathrm{H}), 2.04(\mathrm{~m}, 2 \mathrm{H}), 2.32-2.46$ (complex, 6H), 3.18-3.42 (methylene envelope, 6H), 3.71 (br s, 2H), 4.07 (t, J=5.6 Hz, 2H), 4.32 (s, $1 \mathrm{H}), 6.86(\mathrm{~d}, J=2.6 \mathrm{~Hz}, 1 \mathrm{H}), 7.02(\mathrm{dd}, J=2.8,8.8 \mathrm{~Hz}, 1 \mathrm{H}), 7.11-7.33(\mathrm{~m}, 8 \mathrm{H}), 7.43$ (br d, $J=7.0 \mathrm{~Hz}$, $3 \mathrm{H}) ; \delta_{\mathrm{C}}\left(\right.$ methanol- $\left.d_{4}\right)$ 26.4, 27.2, 29.6, 36.9, 39.6, 42.4, 43.2, 52.6, 53.0, 66.6, 77.2, 114.3, 117.2, 121.4, 128.3, 128.5, 129.0, 129.7, 133.9, 143.7, 158.1, 158.7, 158.8, 170.0, 175.0; m/z (ESI, $50 \mathrm{eV})$ : $m / z$ (\%): 642.5 (100) $[\mathrm{M}+\mathrm{H}]^{+}$. HRMS (ESI') $[\mathrm{M}+\mathrm{H}]^{+}$calcd for $\mathrm{C}_{35} \mathrm{H}_{48} \mathrm{~N}_{9} \mathrm{O}_{3} 642.3880$ found 642.3885 .

\section{N-2-(4-(Bis(4-fluorophenyl)methyl)piperazine-1-carbonyl)-(4-(3-guanidinopropoxy) phenyl)guanidinohexanamide dihydrochloride $(8 b)$}

The diguanidinium compound $\mathbf{8 b}$ was prepared from the diamine $\mathbf{7 b}$ according to the method used to prepare 8a. The product $\mathbf{8 b}$ was obtained as a semiglassy solid (90 $\mathrm{mg}, 84 \%) ; \delta_{\mathrm{H}}\left(\mathrm{methanol}-d_{4}\right)$ 1.40-1.55 (methylene envelope, 2H) 1.55-1.80 (methylene envelope, 4H), 2.04 (t, $J=6.0 \mathrm{~Hz}, 2 \mathrm{H}$ ), 2.25-2.45 (methylene envelope, $6 \mathrm{H}), 3.20(\mathrm{t}, J=6.0 \mathrm{~Hz}, 2 \mathrm{H}), 3.30-3.42$ (methylene envelope, $6 \mathrm{H}$ ), $3.70(\mathrm{br} \mathrm{s}, 2 \mathrm{H}), 4.06(\mathrm{t}, J=6.0 \mathrm{~Hz}, 2 \mathrm{H}), 4.38(\mathrm{br} \mathrm{s}, 1 \mathrm{H}), 6.86(\mathrm{~d}, J=4.0 \mathrm{~Hz}, 1 \mathrm{H}), 7.01(\mathrm{~m}, 5 \mathrm{H}), 7.26$ $(\mathrm{d}, J=10.0 \mathrm{~Hz}, 1 \mathrm{H}), 7.39-7.46(\mathrm{~m}, 5 \mathrm{H}) ; \delta_{\mathrm{C}}\left({\left.\text { methanol- } d_{4}\right)}\right) 25.0,25.8,28.2,35.5,38.1,40.9,41.8,51.0$, $51.3,65.2,73.7,113.0,114.9(\mathrm{~d}, J=21.6 \mathrm{~Hz}), 115.8,127.0,127.6,129.3$ (d, $J=8.0 \mathrm{~Hz}), 132.4,137.9$ $(\mathrm{d}, J=3.0 \mathrm{~Hz}), 156.6,157.2,157.4,161.9(\mathrm{~d}, J=244.5 \mathrm{~Hz}), 168.5,173.6 ; \mathrm{m} / z\left(\mathrm{ESI}^{+}, 50 \mathrm{eV}\right): \mathrm{m} / z(\%)$ : $714.4(10)[\mathrm{M}+\mathrm{HCl}]^{+}, 678.4(50)[\mathrm{M}+\mathrm{H}]^{+}$. HRMS $\left(\mathrm{ESI}^{+}\right)[\mathrm{M}+2 \mathrm{H}+\mathrm{Cl}]^{+}$calcd for $\mathrm{C}_{35} \mathrm{H}_{47} \mathrm{~N}_{9} \mathrm{O}_{3} \mathrm{~F}_{2} \mathrm{Cl}$ 714.3458 found 714.3462; HRMS $\left(\mathrm{ESI}^{+}\right)[\mathrm{M}+\mathrm{H}]^{+}$calcd for $\mathrm{C}_{35} \mathrm{H}_{46} \mathrm{~N}_{9} \mathrm{O}_{3} \mathrm{~F}_{2} 678.3692$ found 678.3685 .

\section{6-Guanidino- $N$-(4-(3-guanidinopropoxy)-2-(4-phenylpiperidine-1-carbonyl)phenyl)hexanamide dihydrochloride (8c)}

The diguanidinium compound $\mathbf{8 c}$ was prepared from the diamine $\mathbf{7 c}$ according to the method used to prepare $8 \mathbf{a}$. The product $\mathbf{8 c}$ was obtained as a semiglassy solid (45 mg, 56\%); $\delta_{\mathrm{H}}$ (methanol- $\left.d_{4}\right) 1.47$ $(\mathrm{m}, 2 \mathrm{H}), 1.62(\mathrm{~m}, 2 \mathrm{H}), 1.73$ (methylene envelope, $4 \mathrm{H}), 1.96(\mathrm{~m}, 1 \mathrm{H}), 2.07(\mathrm{~m}, 2 \mathrm{H}), 2.40(\mathrm{t}, J=7.2 \mathrm{~Hz}$, 2H), 2.83-2.91 (complex, 2H), 3.19 (t, $J=6.8 \mathrm{~Hz}, 2 \mathrm{H}), 3.41$ (t, $J=6.8 \mathrm{~Hz}, 2 \mathrm{H}), 3.49$ (m, 1H), 3.75 (br d, $J=12.8 \mathrm{~Hz}, 1 \mathrm{H}), 4.11(\mathrm{t}, J=5.6 \mathrm{~Hz}, 2 \mathrm{H}), 4.73(\mathrm{br} \mathrm{d}, J=11.6 \mathrm{~Hz}, 1 \mathrm{H}), 6.94(\mathrm{~s}, 1 \mathrm{H}), 7.05$ (dd, $J=2.8$, $8.8 \mathrm{~Hz}, 1 \mathrm{H}), 7.16-7.33$ (complex, 6H); $\delta_{\mathrm{C}}\left(\right.$ methanol- $\left.d_{4}\right)$ 26.3, 27.1, 29.54, 29.58, 33.9, 34.6, 36.7, 
$39.4,42.2,43.5,66.4,114.0,116.9,127.4,127.7,128.3,129.0,129.4,134.1,146.6,158.0,158.5$, 158.6, 169.8, 174.9; $m / z\left(\mathrm{ESI}^{+}, 50 \mathrm{eV}\right): \mathrm{m} / z(\%): 551.5(30)[\mathrm{M}+\mathrm{H}]^{+} \mathrm{HRMS}\left(\mathrm{ES}^{+}\right)[\mathrm{M}+\mathrm{H}]^{+}$calcd for $\mathrm{C}_{29} \mathrm{H}_{43} \mathrm{~N}_{8} \mathrm{O}_{3} 551.3458$ found 551.3431 .

\section{$N$-(2-(4-(Benzo[ $d][1,3]$ dioxol-5-yl)methyl)piperazine-1-carbonyl)-4-(3-guanidinopropoxy) phenyl-6-guanidinohexanamide dihydrochloride $(8 \mathrm{~d})$}

The diguanidinium compound $\mathbf{8 d}$ was prepared from the diamine $\mathbf{7} \mathbf{d}$ according to the method used to prepare 8a. The product $\mathbf{8 d}$ was obtained as a glassy semisolid (50 mg, 93\%); $\delta_{\mathrm{H}}$ (methanol- $\left.d_{4}\right)$ 1.40-1.55 (methylene envelope, 2H), 1.55-1.74 (methylene envelope, 4H), $2.06(\mathrm{~m}, 2 \mathrm{H}), 2.35(\mathrm{t}$, $J=7.2 \mathrm{~Hz}, 2 \mathrm{H}$ ), 2.43 (br s, 2H), 2.53 (br s, 2H), 3.17-3.26 (br t, $J=6.7 \mathrm{~Hz}, 2 \mathrm{H}$ ), 3.34-3.43 (complex, 4H), 3.50 (s, 2H), 3.71 (br s, 2H), $4.08(\mathrm{~m}, 2 \mathrm{H}), 5.92(\mathrm{~s}, 2 \mathrm{H}), 6.76(\mathrm{br} \mathrm{s}, 2 \mathrm{H}), 6.86$ (br s, 1H), 6.88 (d, $J=2.7 \mathrm{~Hz}, 1 \mathrm{H}), 7.04(\mathrm{dd}, J=2.6,8.8 \mathrm{~Hz}, 1 \mathrm{H}), 7.28(\mathrm{~d}, J=8.8 \mathrm{~Hz}, 1 \mathrm{H}) ; \delta_{\mathrm{C}}\left(\right.$ methanol- $\left.d_{4}\right) 26.4,27.2$, 29.6, 36.9, 39.6, 42.4, 53.2, 53.4, 63.1, 66.6, 102.5, 109.0, 110.9, 114.3, 117.3, 124.3, 128.5, 129.0, 131.0, 133.6, 148.7, 149.3, 158.1, 170.0, 174.9; m/z (ESI $\left.{ }^{+}, 50 \mathrm{eV}\right): \mathrm{m} / \mathrm{z}(\%): 610.5(20)[\mathrm{M}+\mathrm{H}]^{+}$. HRMS $\left(\mathrm{ES}^{+}\right)[\mathrm{M}+\mathrm{H}]^{+}$calcd for $\mathrm{C}_{30} \mathrm{H}_{44} \mathrm{~N}_{9} \mathrm{O}_{5} 610.3465$ found 610.3474 .

\subsection{Biology}

\subsection{1. $\mathrm{Ca}_{\mathrm{v}} 2.2$ Radioligand Displacement Assay}

Radioligand binding assays were run in triplicate in 96-well plates at room temperature as previously described [39]. Each assay contained the test compound, radiolabelled peptide ( $7 \mathrm{pM}{ }^{125}$ I-GVIA) and $8 \mu \mathrm{g}$ of crude rat brain membrane, added last. All dilutions were made in assay buffer (20 mM HEPES, $75 \mathrm{mM} \mathrm{NaCl}, 0.2 \mathrm{mM}$ EDTA, $0.2 \mathrm{mM}$ EGTA, $2 \mu \mathrm{M}$ Leupeptin, $2 \mu \mathrm{L}$ apoprotinin (to $30 \mathrm{~mL}$ assay buffer) and $0.1 \% \mathrm{BSA}, \mathrm{pH} 7.4$ ). The final volume in each well was $150 \mu \mathrm{L}$. After shaking for $1 \mathrm{~h}$, the membrane was filtered (Wallac, Finland glass fibre filters pre-soaked in $0.6 \%$ polyethyleneimine) and washed with $20 \mathrm{mM}$ HEPES, $125 \mathrm{mM} \mathrm{NaCl}, \mathrm{pH} 7.4$ on a Tomtec harvester. After addition of scintillant, radioactivity bound to the filter was counted using a 1450 MicroBeta (Wallac, Finland). The data was analyzed using GraphPad Prism 2.0 (GraphPad Software, Inc, San Diego, USA).

\subsubsection{Fluorescence Measurement of Calcium Responses}

SH-SY5Y cells were plated at a density of 30,000 cells/well on 384-well black-walled imaging plates and loaded for $30 \mathrm{~min}$ at $37{ }^{\circ} \mathrm{C}$ with Calcium 4 no-wash dye (Molecular Devices, Sunnyvale, $\mathrm{CA}$ ) diluted in physiological salt solution (PSS; composition: $140 \mathrm{mM} \mathrm{NaCl}, 11.5 \mathrm{mM}$ glucose, $5.9 \mathrm{mM} \mathrm{KCl}, 1.4 \mathrm{mM} \mathrm{MgCl}, 1.2 \mathrm{mM} \mathrm{NaH} \mathrm{PO}_{4}, 5 \mathrm{mM} \mathrm{NaHCO}, 1.8 \mathrm{mM} \mathrm{CaCl}, 10 \mathrm{mM}$ 4-(2-hydroxyethyl)-1-piperazineethanesulfonic acid (HEPES), pH 7.4). SH-SY5Y cells represent an attractive model system and express human $\mathrm{Ca}_{\mathrm{v}} 2.2$ channels in a physiologically relevant context since in native, systems $\mathrm{Ca}_{\mathrm{v}}$ channels are most likely co-expressed with auxiliary $\alpha 2 \delta$ and $\beta$ subunits.

Calcium responses, elicited by addition of $90 \mathrm{mM} \mathrm{KCl}$ and $5 \mathrm{mM} \mathrm{CaCl}_{2}$ in the presence of $10 \mu \mathrm{M}$ nifedipine, were measured using a FLIPR ${ }^{\text {TETRA }}$ fluorescent plate reader (excitation, 470-495 nm; emission, 515-575 $\mathrm{nm}$ ) after 5 min pre-treatment with test compounds in PSS containing $1.8 \mathrm{mM}$ 
$\mathrm{CaCl}_{2}$. Under these conditions, the $\mathrm{Ca}^{2+}$ response elicited by addition of $\mathrm{KCl} / \mathrm{CaCl}_{2}$ is mediated predominantly by GVIA-sensitive $\mathrm{Ca}_{\mathrm{v}} 2.2$ [43]. $\omega$-Conotoxin CVID $(3 \mu \mathrm{M})$ was included as a positive control to define maximal inhibition of $\mathrm{Ca}_{\mathrm{v}} 2.2$ responses.

Fluorescent responses were plotted as response over baseline using ScreenWorks (Molecular Devices, version 3.1.1.4). Concentration-response curves of peak calcium responses, normalized to control responses, were generated using GraphPad Prism (Version 4.00, San Diego, California) using a 4-parameter Hill equation with variable Hill slope fitted to the data.

\subsubsection{Patch Clamp Electrophysiology}

HEK293 cells stably expressing human $\mathrm{Ca}_{\mathrm{v}} 2.2\left(\alpha 1 B+\alpha_{2} \delta+\beta_{3}\right)$, were plated onto $12 \mathrm{~mm}$ coverslips and used for whole-cell patch clamp experiments [47]. Depolarization-activated calcium currents were obtained with the whole-cell recording configuration at room temperature $\left(23-25{ }^{\circ} \mathrm{C}\right)$, using a MultiClamp 700B amplifier and pClamp9.2 software (Molecular Devices, Sunnyvale, CA). The external bath solution contained (in $\mathrm{mM}$ ) $90 \mathrm{NaCl} ; 10 \mathrm{CaCl}_{2} ; 1 \mathrm{MgCl}_{2} ; 10$ HEPES; 30 TEA-Cl; $5 \mathrm{CsCl} ; 10$ glucose, $\mathrm{pH} 7.4$ with TEA-OH $(\sim 310 \mathrm{mOsmol} / \mathrm{kg})$. The patch pipette had a resistance of 1-3 $\mathrm{M} \Omega$, with an internal solution composed of (in $\mathrm{mM}$ ) $130 \mathrm{~K}$-Gluconate; $2 \mathrm{MgCl}_{2} ; 5$ EGTA; 10 HEPES; 5 NaCl; 2 Mg-ATP; 1 Li-GTP, pH 7.2 with Cs-OH ( 300 mOsmol/kg). Calcium currents were elicited from a holding potential of $-80 \mathrm{mV}$ with a depolarizing voltage step to a test potential of $+20 \mathrm{mV}$ for $150 \mathrm{~ms}$, applied every $10 \mathrm{~s}$. Bath perfusion was used to apply compounds, with series resistance typically compensated at $60 \%-80 \%$ and leak subtraction using a $-\mathrm{P} / 4$ pulse protocol.

\section{Conclusions}

The diphenylmethylpiperazine moiety is less likely to lead to toxic effects than the phenoxyaniline substituent present in previously investigated anthranilamide-based GVIA mimics: Anilides are listed in structural alerts for potential adverse drug effects [48] with hepatotoxicity of anilides in certain cases being linked to P-450 activation to benzoquinoneimines in humans [49]. It was therefore pleasing to see that mimics bearing the diphenylmethylpiperazine pharmacophore $(\mathbf{7 a}, \mathbf{7 b}, \mathbf{8 a}, \mathbf{8 b})$ showed very similar activities in the radioligand displacement assay, and improved inhibition of intracellular calcium responses in SH-SY5Y cells, relative to the best of the phenoxyaniline-bearing compounds. Two sets of related compounds that did not possess the diphenylmethyl substituent (7c, 7d, 8c, 8d) were inactive in the radioligand displacement assay, further suggesting that the diphenylmethyl moiety enhances calcium channel affinity in this class of compound.

The radioligand displacement assay employing ${ }^{125} \mathrm{I}-\omega$-conotoxin GVIA is thought to be a specific measure of binding affinity to $\mathrm{Ca}_{\mathrm{v}} 2.2$ channels, because $\omega$-conotoxin GVIA is exceptionally selective for this channel. As this assay does not measure the actual passage of $\mathrm{Ca}^{2+}$ ions though the channel, there is always the possibility that test compounds could cause the ${ }^{125} \mathrm{I}-\omega$-conotoxin to be released from the channel through, for example, an allosteric effect, without actually inhibiting the channel. It was therefore also very pleasing to find that $\omega$-conotoxin GVIA mimetics $(\mathbf{7 c}, \mathbf{7 d}, \mathbf{8 c}, \mathbf{8 d})$ identified to be active in the radioligand displacement assay also induced functional inhibition of intracellular calcium responses in SH-SY5Y neuroblastoma cells and calcium currents in HEK293 cells stably expressing human $\mathrm{Ca}_{\mathrm{v}} 2.2$ channels. These data fill an important gap between binding and downstream functional 
inhibition on median nerve-stimulated rat vas deferans that we have previously observed [50]. These results therefore validate both the use of $\omega$-conotoxin GVIA as a starting point for the design of $\mathrm{Ca}_{\mathrm{v}} 2.2$ channel blockers and the use of the radioligand displacement assay as an initial screening tool for $\mathrm{Ca}_{\mathrm{v}} 2.2$ activity.

The results from the functional assays show the difluoro, diguanidino compound $\mathbf{8 b}$ to be the most effective $\mathrm{Ca}_{\mathrm{v}} 2.2$ channel blocker of the compounds examined in this study. The results obtained with this compound will form the basis for further optimization work, with the aim of improving potency and incorporating more drug-like properties.

\section{Acknowledgments}

The Monash-CSIRO Collaborative Research Support Scheme and CSIRO's Australian Biotech Growth Partnerships Theme are acknowledged for funding. This work was also supported by a NHMRC Program Grant (569927), NHMRC Australian Biomedical Postdoctoral Fellowship (569918, IV) and NHMRC Fellowship (APP1019761, RJL). Meagan Clark is thanked for technical assistance provided during her CSIRO Vacation Scholarship. We thank David Adams, Health Innovations Research Institute, RMIT University, for supporting the electrophysiological studies and valuable input into manuscript preparation.

\section{References}

1. Campbell, J.N.; Meyer, R.A. Mechanisms of neuropathic pain. Neuron 2006, 52, 77-92.

2. Butera, J.A. Current and emerging targets to treat neuropathic pain. J. Med. Chem. 2007, 50, 2543-2546.

3. Kennedy, J.D. Neuropathic pain: Molecular complexity underlies continuing unmet medical need. J. Med. Chem. 2007, 50, 2547-2556.

4. Cox, B.; Denyer, J.C. N-type calcium channel blockers in pain and stroke. Expert Opin. Ther. Pat. 1998, 8, 1237-1250.

5. Bear, B.; Asgian, J.; Termin, A.; Zimmermann, N. Small molecules targeting sodium and calcium channels for neuropathic pain. Curr. Opin. Drug Discov. Develop. 2009, 12, 543-561.

6. Yamamoto, T.; Takahara, A. Recent updates of N-type calcium channel blockers with therapeutic potential for neuropathic pain and stroke. Curr. Top. Med. Chem. 2009, 9, 377-395.

7. Zamponi, G.W.; Feng, Z.P.; Zhang, L.; Pajouhesh, H.; Ding, Y.; Belardetti, F.; Pajouhesh, H.; Dolphin, D.; Mitscher, L.A.; Snutch, T.P. Scaffold-based design and synthesis of potent N-type calcium channel blockers. Bioorg. Med. Chem. Lett. 2009, 19, 6467-6472.

8. Pajouhesh, H.; Feng, Z.P.; Ding, Y.; Zhang, L.; Pajouhesh, H.; Morrison, J.L.; Belardetti, F.; Tringham, E.; Simonson, E.; Vanderah, T.W.; et al. Structure-activity relationships of diphenylpiperazine N-type calcium channel inhibitors. Bioorg. Med. Chem. Lett. 2010, 20, 1378-1383.

9. Pajouhesh, H.; Feng, Z.P.; Zhang, L.; Pajouhesh, H.; Jiang, X.; Hendricson, A.; Dong, H.; Tringham, E.; Ding, Y.; Vanderah, T.W.; et al. Structure-activity relationships of trimethoxybenzyl piperazine N-type calcium channel inhibitors. Bioorg. Med. Chem. Lett. 2012, 22, 4153-4158.

10. Zalicus. Available online: http://www.zalicus.com (accessed on 7 September 2012). 
11. Scott, V.E.; Vortherms, T.A.; Niforatos, W.; Swensen, A.M.; Neelands, T.; Milicic, I.; Banfor, P.N.; King, A.; Zhong, C.; Simler, G.; et al. A-1048400 is a novel, orally active, state-dependent neuronal calcium channel blocker that produces dose-dependent antinociception without altering hemodynamic function in rats. Biochem. Pharmacol. 2012, 83, 406-418.

12. Doherty, G.A.; Bhatia, P.; Vortherms, T.A.; Marsh, K.C.; Wetter, J.M.; Mack, H.; Scott, V.E.; Jarvis, M.F.; Stewart, A.O. Discovery of diphenyl lactam derivatives as N-type calcium channel blockers. Bioorg. Med. Chem. Lett. 2012, 22, 1716-1718.

13. Beebe, X.; Darczak, D.; Henry, R.F.; Vortherms, T.A.; Janis, R.; Namovic, M.; Donnelly-Roberts, D.; Kage, K.L.; Surowy, C.; Milicic, I.; et al. Synthesis and SAR of 4-aminocyclopentapyrrolidines as $\mathrm{N}$-type $\mathrm{Ca}^{2+}$ channel blockers with analgesic activity. Bioorg. Med. Chem. 2012, 20, 4128-4139.

14. Abbadie, C.; McManus, O.B.; Sun, S.-Y.; Bugianesi, R.M.; Dai, G.; Haedo, R.J.; Herrington, J.B.; Kaczorowski, G.J.; Smith, M.M.; Swensen, A.M.; et al. Analgesic effects of a substituted N-triazole oxindole (TROX-1), a state-dependent, voltage-gated calcium channel 2 blocker. J. Pharm. Exp. Ther. 2010, 334, 545-555.

15. Tyagarajan, S.; Chakravarty, P.K.; Park, M.; Zhou, B.; Herrington, J.B.; Ratliff, K.; Bugianesi, R.M.; Williams, B.; Haedo, R.J.; Swensen, A.M.; et al. A potent and selective indole N-type calcium channel $(\mathrm{Ca}(\mathrm{v}) 2.2)$ blocker for the treatment of pain. Bioorg. Med. Chem. Lett. 2011, 21, 869-873.

16. Subasinghe, N.L.; Wall, M.J.; Winters, M.P.; Qin, N.; Lubin, M.L.; Finley, M.F.A.; Brandt, M.R.; Neeper, M.P.; Schneider, C.R.; Colburn, R.W.; et al. A novel series of pyrazolylpiperidine N-type calcium channel blockers. Bioorg. Med. Chem. Lett. 2012, 22, 4080-4083.

17. Olivera, B.; Teichert, R.W. Diversity of the neurotoxic Conus peptides: a model for concerted pharmacological discovery. Mol. Interv. 2007, 7, 251-260.

18. Lewis, R.J.; Dutertre, S.; Vetter, I.; Christie, M.J. Conus venom peptide pharmacology. Pharmacol. Rev. 2012, 64, 259-298.

19. Adams, D.J.; Callaghan, B.; Berecki, G. Analgesic conotoxins: block and G protein-coupled receptor modulation of $\mathrm{N}$-type $(\mathrm{Ca}(\mathrm{v}) 2.2)$ calcium channels. Br. J. Pharm. 2012, 166, 486-500.

20. Pexton, T.; Moeller-Bertram, T.; Schilling, J.M.; Wallace, M.S. Targeting voltage-gated calcium channels for the treatment of neuropathic pain: a review of drug development. Expert Opin. Investig. Drugs 2011, 20, 1277-1284.

21. Kolosov, A.; Goodchild, C.S.; Cooke, I. CNSB004 (Leconotide) causes antihyperalgesia without side effects when given intravenously: A comparison with ziconotide in a rat model of diabetic neuropathic pain. Pain Med. 2010, 11, 262-273.

22. Kolosov, A.; Aurini, L.; Williams, E.D.; Cooke, I.; Goodchild, C.S. Intravenous injection of leconotide, an omega conotoxin: Synergistic antihyperalgesic effects with morphine in a rat model of bone cancer pain. Pain Med. 2011, 12, 923-941.

23. Baell, J.B.; Forsyth, S.A.; Gable, R.W.; Norton, R.S.; Mulder, R.J. Design and synthesis of type-III mimetics of omega-conotoxin GVIA. J. Comput. Aided Mol. Des. 2001, 15, 1119-1136.

24. Baell, J.B.; Duggan, P.J.; Lok, Y.P. $\omega$-conotoxins and approaches to their non-peptide mimetics. Aust. J. Chem. 2004, 57, 179-185. 
25. Guo, Z.-X.; Cammidge, A.N.; Horwell, D.C. Dendroid peptide structural mimetics of omega-conotoxin MVIIA based on a 2(1H)-quinolinone core. Tetrahedron 2000, 56, 5169-5175.

26. Menzler, S.; Bikker, J.A.; Horwell, D.C. Synthesis of a non-peptide analogue of omega-conotoxin MVIIA. Tetrahedron Lett. 1998, 39, 7619-7622.

27. Menzler, S.; Bikker, J.A.; Suman-Chauhan, N.; Horwell, D.C. Design and biological evaluation of non-peptide analogues of omega-conotoxin MVIIA. Bioorg. Med. Chem. Lett. 2000, 10, 345-347.

28. Schroeder, C.I.; Smythe, M.L.; Lewis, R.J. Development of small molecules that mimic the binding of omega-conotoxins at the N-type voltage-gated calcium channel. Mol. Divers. 2004, 8, 127-134.

29. Baell, J.B.; Duggan, P.J.; Forsyth, S.A.; Lewis, R.J.; Lok, Y.P.; Schroeder, C.I. Synthesis and biological evaluation of nonpeptide mimetics of omega-conotoxin GVIA. Bioorg. Med. Chem. 2004, 12, 4025-3037.

30. Duggan, P.J.; Lewis, R.J.; Lok, Y.P.; Lumsden, N.G.; Tuck, K.L.; Yang, A. Low molecular weight non-peptide mimics of omega-conotoxin GVIA. Bioorg. Med. Chem. Lett. 2009, 19, 2763-2765.

31. Baell, J.B.; Duggan, P.J.; Forsyth, S.A.; Lewis, R.J.; Lok, Y.P.; Schroeder, C.I.; Shepherd, N.E. Synthesis and biological evaluation of anthranilamide-based non-peptide mimetics of omega-conotoxin GIVA. Tetrahedron 2006, 62, 7284-7292.

32. Andersson, A.; Baell, J.B.; Duggan, P.J.; Graham, J.E.; Lewis, R.J.; Lumsden, N.G.; Tranberg, C.E.; Tuck, K.L.; Yang, A. Omega-conotoxin GVIA mimetics based on an anthranilamide core: effect of variation in ammonium side chain lengths and incorporation of fluorine. Bioorg. Med. Chem. 2009, 17, 6659-6670.

33. Lauri, G.; Bartlett, P.A. CAVEAT: A program to facilitate the design of organic molecules. J. Comput. Aided Mol. Des. 1994, 8, 51-66.

34. Gould, R.J.; Murphy, K.M.; Reynolds, I.J.; Snyder, S.H. Antischizophrenic drugs of the diphenylbutylpiperidine type act as calcium channel antagonists. Proc. Natl. Acad. Sci. USA 1983, $80,5122-5125$.

35. Ito, M.; Koyakumaru, K.; Ohta, T.; Takaya, H. A simple and convenient synthesis of Alkyl Azides under mild conditions. Synthesis 1995, 4, 376-378.

36. Shpiro, N.; Marquez, R. An improved synthesis of the potent MEK inhibitor PD184352. Synth. Commun. 2005, 35, 2265-2269.

37. Handlon, A.L.; Oppenheimer, N.J. Thiol reduction of 3'-azidothymidine to 3'-aminothymidine: kinetics and biomedical implications. Pharm. Res. 1988, 5, 297-299.

38. Bernatowicz, M.S.; Wu, Y.; Matsueda, G.R. 1H-Pyrazole-1-carboxamidine hydrochloride an attractive reagent for guanylation of amines and its application to peptide synthesis. J. Org. Chem. 1992, 57, 2497-2502.

39. Lewis, R.J.; Nielsen, K.J.; Craik, D.J.; Loughnan, M.L.; Adams, D.A.; Sharpe, I.A.; Luchian, T.; Adams, D.J.; Bond, T.; Thomas, L.; et al. Novel omega-conotoxins from Conus catus discriminate among neuronal calcium channel subtypes. J. Biol. Chem. 2000, 275, 35335-35344.

40. Wagner, J.A.; Snowman, A.M.; Biswas, A.; Olivera, B.M.; Snyder, S.H. omega-Conotoxin GVIA binding to a high-affinity receptor in the brain: Characterization, calcium sensitivity, and solubilization. J. Neurosci. 1988, 8, 3354-3359. 
41. Mould, J.; Yasuda, T.; Schroeder, C.I.; Beedle, A.M.; Doering, C.J.; Zamponi, G.W.; Adams, D.J.; Lewis, R.J. The alpha2delta auxiliary subunit reduces affinity of omega-conotoxins for recombinant N-type $\left(\mathrm{Ca}_{\mathrm{v}} 2\right.$.2) calcium channels. J. Biol. Chem. 2004, 279, 34705-34714.

42. Reeve, H.L.; Vaughan, P.F.; Peers, C. Calcium channel currents in undifferentiated human neuroblastoma (SH-SY5Y) cells: Actions and possible interactions of dihydropyridines and omega-conotoxin. Eur. J. Neurosci. 1994, 6, 943-952.

43. Reuveny, E.; Narahashi, T. Two types of high voltage-activated calcium channels in SH-SY5Y human neuroblastoma cells. Brain Res. 1993, 603, 64-73.

44. Morton, A.J.; Hammond, C.; Mason, W.T.; Henderson, G. Characterisation of the L- and N-type calcium channels in differentiated SH-SY5Y neuroblastoma cells: calcium imaging and single channel recording. Mol. Brain Res. 1992, 13, 53-61.

45. Toselli, M.; Masetto, S.; Rossi, P.; Taglietti, V. Characterization of a Voltage-dependent Calcium Current in the Human Neuroblastoma Cell Line SH-SY5Y During Differentiation. Eur. J. Neurosci. 1991, 3, 514-522.

46. Pangborn, A.B.; Giardello, M.A.; Grubbs, R.H.; Rosen, R.K.; Timmers, F.J. Safe and Convenient Procedure for Solvent Purification. Organometallics 1996, 15, 1518-1520.

47. Dai, G.; Haedo, R.J.; Warren, V.A.; Ratliff, K.S.; Bugianesi, R.M.; Rush, A.; Williams, M.E.; Herrington, J.; Smith, M.M.; McManus, O.B.; et al. A high-throughput assay for evaluating state dependence and subtype selectivity of Cav2 calcium channel inhibitors. Assay Drug Dev. Technol. 2008, 6, 195-212.

48. Edwards, P.J.; Sturino, C. Managing the Liabilities Arising from Structural Alerts: A Safe Philosophy for Medicinal Chemists. Curr. Med. Chem. 2011, 18, 3116-3135.

49. Kalgutkar, A.S.; Gardner, I.; Obach, R.S.; Shaffer, C.L.; Callegari, E.; Henne, K.R.; Mutlib, A.E.; Dalvie, D.K.; Lee, J.S.; Nakai, Y.; et al. A comprehensive listing of bioactivation pathways of organic functional groups. Curr. Drug Metab. 2005, 6, 161-225.

50. Norton, R.S.; Baell, J.B.; Angus, J.A. Calcium Channel Blocking Polypeptides: Structure, Function, and Molecular Mimicry. In Calcium Channel Pharmacology; McDonough, S.I., Ed.; Plenum Press: New York, NY, USA, 2003; pp. 143-179.

Samples Availability: Available from the authors.

(C) 2012 by the authors; licensee MDPI, Basel, Switzerland. This article is an open access article distributed under the terms and conditions of the Creative Commons Attribution license (http://creativecommons.org/licenses/by/3.0/). 